\title{
The Integrative Five-Fluid Circulation System in the Human Body
}

\author{
Peter Chin Wan Fung1, Regina Kit Chee Kong² \\ ${ }^{1}$ Division of Medical Physics, Department of Medicine, University of Hong Kong, Hong Kong, China \\ ${ }^{2}$ School of Traditional Chinese Medicine, Southern Medical University, Guangzhou, China \\ Email: peterallegro333@gmail.com
}

How to cite this paper: Fung, P.C.W. and Kong, R.K.C. (2016) The Integrative FiveFluid Circulation System in the Human Body. Open Journal of Molecular and Integrative Physiology, 6, 45-97.

http://dx.doi.org/10.4236/ojmip.2016.64005

Received: October 18, 2016

Accepted: November 15, 2016

Published: November 18, 2016

Copyright $\odot 2016$ by authors and Scientific Research Publishing Inc. This work is licensed under the Creative Commons Attribution International License (CC BY 4.0).

http://creativecommons.org/licenses/by/4.0/

\section{Abstract}

Water is the key medium to transport numerous constituents and to provide a platform for physiological processes to take place in the living organisms in general; it also participates actively in many of these processes. In humans, there are different vehicles to contain water and its constituents. Our objective is to find out whether there is an overall water-base circulation system in the human body by analyzing the updated findings of different research groups on the physiological functions of various seemingly isolated fluid systems. By 1963, there were five separate fluid systems discovered in mammalians: (i) The Primo Vasculature Fluid (PVF) with protein precursors and micro cells held in the Primo Vasculature System (PVS). (ii) Blood with its constituents held in the cardio vasculature. (iii) Extracranial interstitial fluid (ISF) whose vehicle had a very irregular structure-the interstitium all over the body. (iv) The cerebrospinal fluid had been considered to be within the brain ventricles and spinal canal. (v) The extra-cranial lymphatic system which drained ISF, and had been known to join the subclavian vein. Fluid (i) was first reported in 1963 and fluids (ii) to (v) have been known for many decades, but the failure to detect a lymphatic system inside the skull has also been a mystery for many decades. The intra-cranial ISF (which we name as BISF) has drawn little attention, apart from discussing the mechanism of the blood-brain-barrier. During the past decade, there has been direct evidence indicating that CSF and BISF are actually mixed. After that, the intracranial lymphatic system was discovered and confirmed in animal models only slightly over one year back, and we called such fluid as glymphatic-fluid. After reviewing the stated "classical" five fluid systems together with the new findings in Sections 2 - 7, we propose, for the first time, that the PVF, the blood, ISF, a mixture of CSF-BISF, and a mixture of glymphatic-fluid and lymph form an integrative circulation system in water base in the human and other mammalian bodies, as schematically represented in the last section. In this paper, we point out the positive correlation of chronic neuro degenerative diseases such as Alzheimer's disease, Parkinson's diseases 
and the insufficient brain wastes clearance by the glymphatic system. We also discuss the role played by the venous vessels as part of such clearance in upright posture. Moreover, simple non-invasive maneuver techniques are introduced here, as one example of enhancement of glymphatic fluid flow out of the skull to join the lymphatic system. A series of questions are raised in Section 8, the answers to which would help us to understand the transition from physio- to pathological states in the development of many diseases. Detailed analysis of this paper leads us to consider that research in understanding this integrative circulation system is only at the infancy stage, and fluid dynamics investigation seems to be the plausible modality of approach in the near future.

\section{Keywords}

Glymphatic System, Primo Vasculature System, Cerebrospinal Fluid, Intra-Cranial and Extra-Cranial Interstitial Fluids, Lymph, Cardiovascular System, Integrative Five-Fluid Circulation System, Neuro Degenerative Diseases

\section{Introduction}

Water molecules have polar structure, and form protons/hydronium ions, hydroxyl ions among the water molecules themselves, making water a special fluid to function as the most convenient medium to transport both hydrophilic and hydrophobic bio-molecules, and as a medium for numerous biochemical and biophysical interactions in the body. There are many different anatomical structures in different organs/organelles because they carry out different functions. Thus inevitably the fluid contents (water plus the solutes and insoluble peptides/proteins) in different parts of the body are different. Moreover, the ratios of the amounts of bound and free water in organs such as skin, Achilles tendon, tracheal cartilage, muscle and others vary from site to site [1]. Thus knowledge of the state of water, its movement (carrying with it solutes and insoluble biochemical constituents, proteins and cells) as well as the features/conditions of the physical vehicles that bring water and its constituents around is of prime importance in medicine.

Note that the overall complicated integrative system contains several fluid systems. It will be confusing to the reader if we review the development and special features of each fluid system in details in this section. Such discussion will be presented in Sections 2-7. Rather, to begin with, we will present a possible origin of the first fluid system (PVS) here. After that, we will give a brief picture of each fluid system and outline the content of the paper, so that the reader might have an overall view of this investigation after reading this section.

As early as 1963, Bong Han Kim [2] already discovered distinctive tube-like structure (as a water carrying vehicle system) in different parts of some animals' bodies. The diameters of the ducts were found to fall in the range of several tens to $100 \mu \mathrm{m}$. Networks with such ducts joining to nodes (somewhat similar to the morphology of lymphatic 
nodes) were found. The progress was slow at first, due to the difficulty in finding the appropriate tracers, and the unawareness of the existence of such fluid-carrying vehicle system. During the past decade, many experimental revelations of such systems across species, including human, have been successful by application of different staining techniques. Starting from 2009, such a "new" system was named the Primo Vasculature System (PVS), the vessels are called Primo Vessels (PVs) and the joints/nodal structures are termed Primo Nodes (PNs), whereas the fluid inside such vessels is called Primo Vasculature Fluid (PVF).

The PVF has been found to contain stem cell niches, microcells, basophilic granules, hormones, peptides, precursors of proteins and proteins; a detailed review is presented in Section 2. This system has then been hypothesized to be a circulation system. We further hypothesize that PVS is the first circulation system before the blood circulation system develops in the embryo. The flow speed of the PVF has been measured to be within the range of $100-800 \mu \mathrm{m} / \mathrm{second}$ in a number of animal models. These values are significantly higher than the lymph flow speed measured in lymphatic vessels associated with PVS; the flow speeds of PVF are much higher than the flow speed range of the interstitial fluids ( $\sim 10 \mu \mathrm{m} / \mathrm{second}$, Section 4$)$ in different parts of the human body.

We hypothesize that the PVS helps to develop the endoderm, mesoderm, and later the ectoderm in the embryo. There is so far no concrete experimental report regarding to the origin of this system at this present time, and we can only speculate according to the simple model in relation to the embryonic growth [3], starting from the very early stage.

First, let us consider a mystery in embryonic development. When an immature egg cell (primary oocyte) undergoes its first division (meiosis), the daughter cells are diploid (each cell contains two chromosomes from each parent). Whereas the DNA of each daughter cell is the same, one daughter cell contains much more cellular contents (cytoplasm) than the other. The much smaller cell is called a primary polar body and the cell with the much larger amount of cytoplasm is called a secondary oocyte. Then both cells undergo mitosis, a process leading to haploid daughter cells (each cell has only one chromosome from each parent). The secondary oocyte undergoes uneven cell division. This produces a mature ovum (mature egg cell) and another polar body. The primary polar body also undergoes mitosis and makes two secondary polar bodies. Usually, all polar bodies will die via apoptosis. The function of the polar bodies is poorly understood.

Based on the revelation of a complicated network on the vitelline and white thick albumin and some dots (which were speculated to be DNA containing bodies), it has been speculated in [3] that polar bodies are transformed into the PVS mentioned above as an extraembryonic tissue. The vessels in PVS with ample "ingredients" have been speculated to control the oocyte maturation process, providing a possible picture on the role and destination of the polar bodies. Further verification is needed to justify this hypothesis, but we have a tentative start of our five-fluid circulation model.

It is established in developmental biology that blood vessels originate from embryonic mesoderm, which also develops connective tissues. The pluripotent stem cells diffe- 
rentiate into the elements of the blood. The arteries and venous vessels develop at the same time. The heart, brain, and spine emerge as extensions of the blood vessels, and blood with the associated cells and proteins becomes the second member of the fivefluid circulation system of our model. We now jump to consider an adult human body. There has been ample investigation on the structure of the arterial vessels and the flow characteristics. In Section 3, we will give a very brief sketch and highlight a number of usually unfamiliar characteristics of the blood system, which are related to discussions in Sections $6,7 \& 8$. Arterial blood supplies water, nutrients, oxygen, together with immunity cells to the third fluid of the five-fluid system, namely the interstitial fluid (ISF) which is kept in a very irregular anatomical structure of the whole body-the interstitium. The ISF participates in very important physiological functions by passing on the above mentioned constituents/elements to nourish the organs/organelles such as muscle cells, cartilage, bone cells plus other cell groups to perform their normal duties. Some proteins and carbon dioxide return from the ISF back to the blood. We use the term ISF to represent extra-cranial interstitial fluid. In Section 4, we briefly sketch some special features of the interstitium and highlight some crucial properties of ISF. We then analyze the generation of the classically known cerebrospinal fluid (CSF, which has passed through the blood-CSF barrier), including the contribution from arterial supply from extra-cranial source based on recent investigation, in Section 5. Whereas CSF is generated in the brain ventricles, arterial vessels in the brain parenchyma also supply interstitial fluid, via the blood-brain barrier to the brain cortex. We term this intracranial ISF as BISF. In Section 5, we also analyze the mixing process of CSF and BISF; we call the resulting mixture CSF-BISF, the fourth fluid in our system. This process has only been discovered within the past decade. The ISF must carry the metabolic wastes and debris of antigens (being broken down by immunity cells) in the interstitium to another fluid for identification and clearance-the lymphatic system, which is the fifth fluid system in this analysis. We review the function of the extracranial major lymphatic organs and lymphatic vessels in Section 6 .

Likewise, the CSF-BISF fluid from the brain must also be drained. The drainage of the metabolic wastes from the brain has been considered to be through venous vessels for many decades. Since the brain is a heavy-duty organ, one big mystery remains for all this time: the missing intra-cranial lymphatic system. More precisely, the key question asked is: how does the cerebrospinal system drain the wastes (including the $\beta$ Amyloid and tau proteins, the accumulation of which are correlated strongly with Alzheimer's disease, Parkinson's disease, plus other brain disorders) without an associated lymphatic system inside the skull? In Section 7, we discuss the intracranial lymphatic system - the glymphatic network system which has just been discovered and confirmed in animal models in the past one/two years [4]. We put forth the notion that such a system also exists in humans. Some simple maneuver techniques developed by the present authors, using Bian stone tools, are introduced to help brain wastes clearance. We summarize the function of the integrative five-fluid system in Section 8. Our analysis infers that understanding the fluid dynamics of this combined system is important 
in analyzing physio-pathological states. We also raise some crucial questions to be answered in future research.

\section{The Primo Vasculature System}

\subsection{The PVSs Were Found in Rat, Mouse, Rabbit, Cow, Pig, Dog, and Human}

Threadlike structures, different from all the circulation and nerve systems known, were first reported by Kim in 1963 [2] [5]. Since then, quite a number of studies have reported the revelation of these transparent vessels [6] [7] [8] [9]. Table 1 lists a summary of representative papers (not fully listed) in recent years, stating the locations, species of living organisms and some particulars where PVSs were found by experiments. The average of the largest diameters in a number of PVs revealed is indicated by $\mathrm{D}$, if such data are available, and $\mathrm{W}$ is the average diameter of the lymph vessels enclosing the PVs, in cases where PVs are found to be inside lymph vessels. $\mathrm{N}$ is the

Table 1. Revelation of the Primo Vasculature System in Different Organisms.

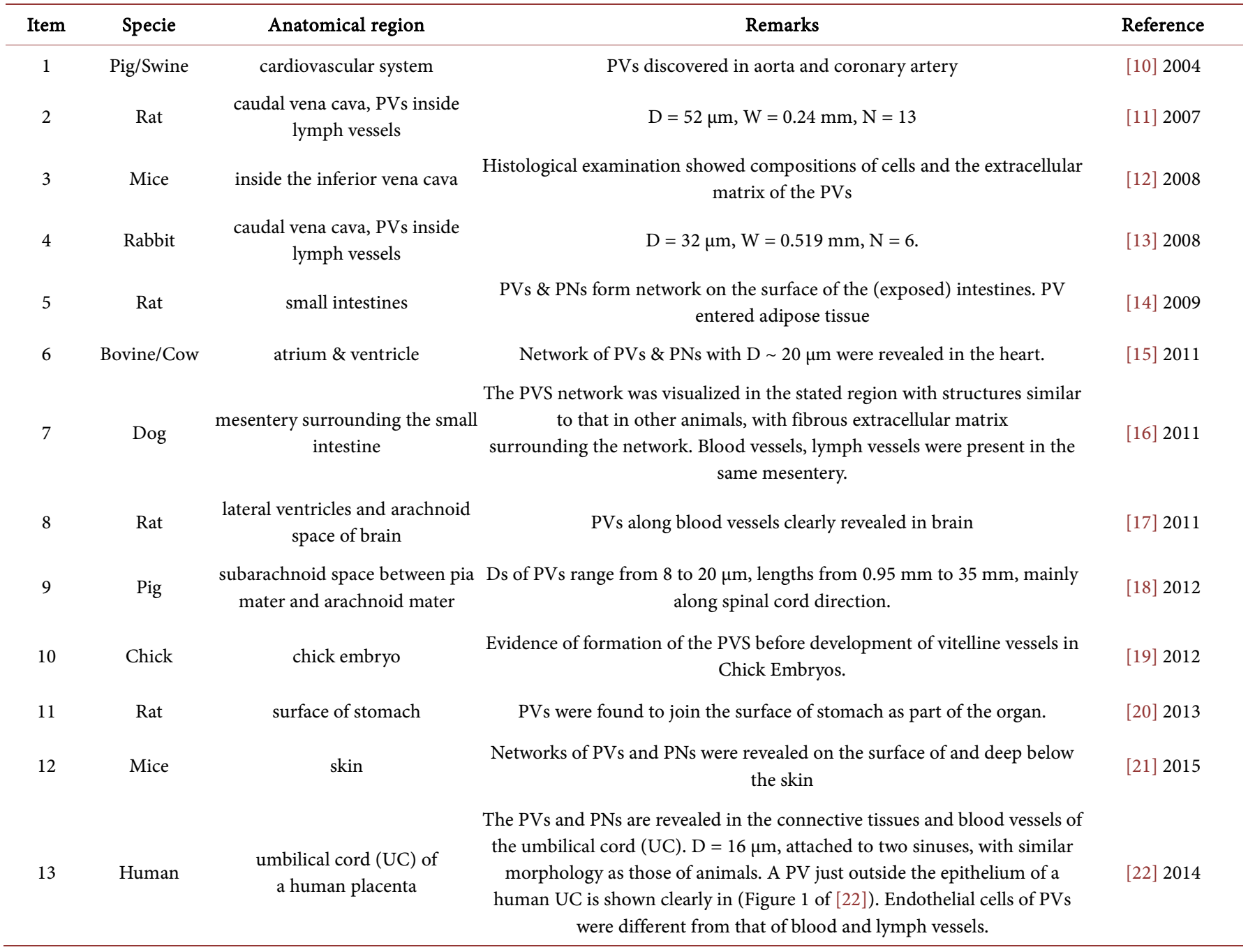


number of specimens if available in the publications; special remark lists certain special features in brief. The last number in the last column is the year of publication.

\subsection{Classification and General Characteristics of the Primo Vasculature Systems among the Species Listed in the Last Section}

\section{(1) Definition of PVS}

A unit of a PV, called a ductile (similar to a collagen molecule in a collagen fibril) in the PVS has a thin layer, composed of endothelial cells with rod-shaped nuclei. It is surrounded by an external membrane built of cells similar to smooth muscle cells or epithelial cells yet to be confirmed [23]. The endothelial cells have rod-shaped nuclei, and fine argentaffin fibers. A membrane wraps around several ductules to form a PV. Fibrous and amorphous materials are found in the interluminal space of a typical PV. PVs are joined to nodes called PNs to form a network.

(2) Intravascular PVS

There are reticular fibers, extracellular matrices (ECM) between ductules. One class of PVs (called intravascular class) are systematically distributed inside and along the blood and lymphatic vessels, often joined to one or a small number of corpuscles/ nodes. Some of these PVs are found to leave the lymphatic vessels and join the adipose tissues [5].

(3) Extravascular PVS

There are PVs and PNs running along, but outside the blood and lymphatic vessels, and nerves. This class of network may be called the extravascular class. There are thick connective tissues surrounding them. In the lumens of these PVs and inside the PNs, many chromaffin granules are revealed [5].

(4) Organ Surface PVS

Another class (called organ surface class) of PVs and PNs are joined together, forming a freely floating network on the surfaces of internal organs, such as that found in the adipose tissues on the intestine [14]. These PVs are not associated with blood or lymphatic vessels. In the lumens of the PVs and inside PVs in this class of network, there are cells possessing, bright cytoplasm and basophilic granules [15].

(5) Sub-system Nerve of PVS

Class $\mathrm{N}$ may be designated to those PVs and PNs floating in the cerebrospinal fluid (CSF) in the brain, with branches distributed in the parenchyma of the central nervous system. Sub-systems N (nerve) are also found in the peripheral nervous system [9].

(6) Intra-organ subsystem of PVS

Inside the parenchyma of internal organs, PVs and PNs are also found in animal models [9]. This class may be called class I, meaning intra-organ subsystem.

(7) Some features of PNs

The PNs have oval shape with a width of $0.1-0.5 \mathrm{~mm}$ and length of $0.5-1 \mathrm{~mm}$. The ends of a node are usually linked to PVs with lengths $3-6 \mathrm{~cm}$ and diameters in the range of few tens to $100 \mu \mathrm{m}$. There are reticular fibers forming a thin net to support the positions of the network of PVs and PNs, similar to the reticular fibers (built of colla- 
gen fibrils/fibers) supporting the blood vessels [9].

(8) The fluids inside the PVs found according to early studies are [2] [5]:

i) DNA \& RNA

ii) Amino acids: 19 amino acids found, including some essential ones.

iii) Nitrogen content: 3.12 to $3.40 \%$.

iv) Lipid: $0.57 \%-1.00 \%$.

v) Reduced sugar: $0.10 \%-0.12 \%$.

vi) Hyaluronic acid.

vii) Free mono nucleotides: 16 types so far found.

(9) Motion of PVs

There are transverse and longitudinal oscillatory types of motion of a typical PV, presumably propelling the fluid (PVF) inside.

(10) PVS and Tumor

PVS has been found to be more densely populated in the proximity of a number of tumors [24].

We show in Figure 1 below some photos revealing the PVS in rabbit as reported in [25] with permission.

\subsection{Contents of the Primo Fluid according to Recent Investigation, and Its Implication}

The Primo Fluid inside a PVS system on the tissues above the intestine of rabbit model was extracted. Using a solution digestion technique, proteomic analysis carried out in [26] identified 81 proteins in such fluid and 207 proteins in the cells composing the ducts. Following, employing the gene ontology clustering analysis to study these proteins indicate that these proteins pertain to processes involved in various physiological processes and body development. We shall briefly analyze and classify 49 , as examples, out of the 81 items in Table 2, according to their main functions in humans, though
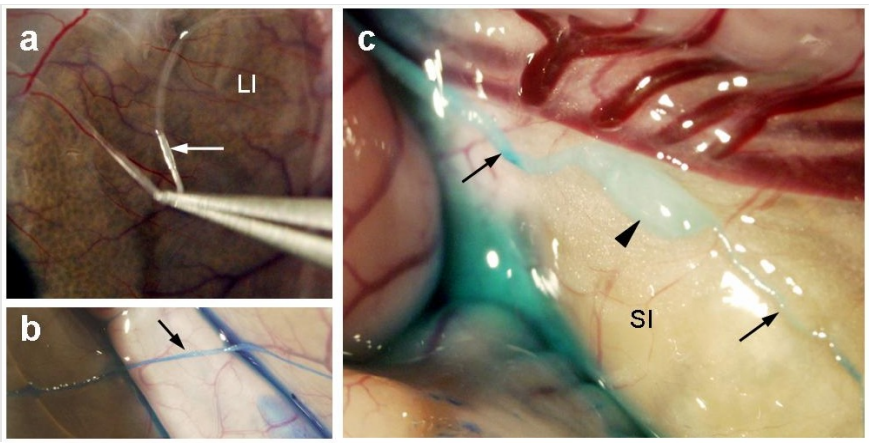

Figure 1. Stereomicroscopic images of PVs and PNs on the surface of the region with large intestine of rabbit. (a) The white arrow indicates a movable Primo Vessel revealed on large intestine surface before staining. (b) The black arrow shows a PV after methylene blue staining. (c) The black arrow head points to a Primo Node/Corpuscle which is connected to two PVs. Figures 1(a)-(c) is reproduced from [25] with permission of the publisher JAMS and the corresponding author Prof. K. S. Soh. 
Table 2. (a) Life energy generation and related metabolism; (b) Blood cells synthesis/regulation, iron ion transport, \& angiogenesis; (c) Proteins interacting with key positive ions $\mathrm{Ca}^{2+}, \mathrm{Na}^{+}, \mathrm{K}^{+}$, or $\mathrm{H}^{+}$, and proteins involved in other signaling pathways; (d) Proteins involved in body growth and development; (e) Cholesterol/hormone transport or synthesis, Vitamins transport, mechanotransduction, tumor suppression and DNA repair.

(a)

\begin{tabular}{|c|c|c|}
\hline Serial No & Protein/precursor & Main function involvement \\
\hline 21536286 & brain creatine kinase & energy generation during brain function \\
\hline 125307 & creatine kinase M-type & life energy generation/metabolism \\
\hline 113608 & fluctose- biphosphate aldolase A & glycolysis \\
\hline 136066 & triosephosphate isomerase (TIM) & life energy production via glycolysis \\
\hline 6093713 & glycogen phosphorylase, muscle form & carbohydrate metabolism \\
\hline 2851533 & pyruvate kinase isozymes M1/M2 & ATP and pyruvate generation \\
\hline 20141354 & $\beta$-enolase & glycolysis \\
\hline 1169794 & glyceraldehyde-3- phosphate dehydrogenase & supply of life energy and carbon \\
\hline 126050 & L-Lactate dehydrogenase A chain & metabolism \\
\hline 229506 & aldolase C (ALDOC) & energy generation in the brain and other tissues \\
\hline 21536288 & muscle creatine kinase & catalysis of ATP generation in heavy duty cells \\
\hline 5032009 & glycogen phosphorylase & life energy generation \\
\hline 34577110 & aldolase A & energy in liver, kidney and intestine \\
\hline 33286472 & pyruvate kinase 3 isoform 2 & life energy generation \\
\hline 4507031 & $\begin{array}{l}\text { solute carrier family } \\
\text { (sodium/glucose cotransporter) }\end{array}$ & glucose and galactose uptake from intestine \\
\hline
\end{tabular}

(b)

\begin{tabular}{|c|c|c|}
\hline Serial No & Protein/precursor & Main function involvement \\
\hline 6175087 & serotransferrin precursor & transport of ferric ions \\
\hline 122475 & hemoglobin subunit $\alpha-1 / 2$ & $\begin{array}{l}\text { transport of oxygen, carbon dioxide and nitric oxide } \\
\text { and plays role as an anti-oxidant }\end{array}$ \\
\hline 122676 & hemoglobin subunit $\beta-1 / 2$ & $\begin{array}{l}\text { transport of oxygen, carbon dioxide and nitric oxide } \\
\text { and plays role as an anti-oxidant }\end{array}$ \\
\hline 1708184 & hemopexin precursor & heme-binding protein, constituent of blood plasma \\
\hline 4504345 & $\alpha$-2 globin. & red blood cell synthesis \\
\hline 4504349 & $\beta$-globin & red blood cell synthesis \\
\hline 11761629 & $\begin{array}{l}\text { fibrinogen, alpha poly- peptide } \\
\text { isoform alpha }\end{array}$ & blood coagulation \\
\hline 2494026 & histidine-rich glycoprotein precursor & $\begin{array}{l}\text { muti-functions: cell activities, angiogenesis, pathogen } \\
\text { clearance, fibrinolysis }\end{array}$ \\
\hline
\end{tabular}


(c)

\begin{tabular}{|c|c|c|}
\hline Serial No & Protein/precursor & Main function involvement \\
\hline 44889024 & serum albumin precursor & $\begin{array}{l}\text { binding to the three most important positive ions, } \\
\text { water, some hormones, it is the main protein in blood }\end{array}$ \\
\hline 118600944 & parvalbumin $\alpha$ & $\begin{array}{l}\text { calcium ion is a multi-functioned second messenger. } \\
\text { Parvalbumin } \alpha \text { is a calcium-binding protein }\end{array}$ \\
\hline 62632750 & ATPase, class VI, type II B & transporter of positively charged ions \\
\hline 4557729 & $\begin{array}{l}\text { precursor of voltage-gated potassium } \\
\text { channels sub-family, member } 2 \text { isoform }\end{array}$ & $\begin{array}{l}\text { regulate electro-cardiac signals, is transporter of } \\
\text { positively charged ions }\end{array}$ \\
\hline 4506813 & voltage-gated sodium channel & $\begin{array}{l}\text { provides means of electrical signals through nerves, } \\
\text { skeletal muscle and heart }\end{array}$ \\
\hline 8923844 & soluble adenylyl cyclase & $\begin{array}{l}\text { effector molecule of important signal transduction } \\
\text { pathway, with special function of sensing bicarbonate }\end{array}$ \\
\hline 40254842 & centaurin $\beta 2$ & $\begin{array}{l}\text { multi-signaling pathways and hence involved in } \\
\text { multi-cell functions }\end{array}$ \\
\hline \multicolumn{3}{|c|}{ (d) } \\
\hline Serial No & Protein/precursor & Main function involvement \\
\hline 130488651 & serpin peptidase inhibitor, grade $\mathrm{F}$ & $\begin{array}{l}\text { regulation of array of biological processes, including } \\
\text { growth and immunity }\end{array}$ \\
\hline 21542114 & lumican & $\begin{array}{l}\text { as a constituent in the interstitium, and cornea of the } \\
\text { eye }\end{array}$ \\
\hline 4557871 & transferrin & transport of iron to proliferating cells \\
\hline 156523970 & $\alpha$-HS-glycoprotein (AHSG) & brain, bone development with endocytosis capability \\
\hline 4502101 & annexin 1 & cell group formation and cell death signaling \\
\hline 22547186 & $\begin{array}{l}\text { serine hydroxymethy-transferase } 1 \\
\text { isoform } 1\end{array}$ & cytoplasm synthesis \\
\hline 4503063 & crystalline beta-B2 & formation of eye lens \\
\hline 130498871 & inter- $\alpha$ trypsin inhibitor heavy chain 2 & connective tissue structure \\
\hline 112876 & $\alpha 1$ - antiproteinase F precursor & connective tissues regulation \\
\hline
\end{tabular}

(e)

\begin{tabular}{lll}
\hline Serial No & Protein/precursor & Main function involvement \\
\hline 113996 & apolipoprotein A-1 precursor & $\begin{array}{l}\text { transport of unused cholesterol back to liver } \\
\text { synthesis of high density lipoprotein and tissue reverse } \\
\text { cholesterol transport as the last item }\end{array}$ \\
1722804 & vitamin D-binding protein precursor & vitamin D-transport \\
32483410 & vitamin D-binding protein & vitamin D-transport \\
136466 & transthyretin (prealbumin) & transportation of hormone and Vitamin A \\
139654 & vitronectin precursor & mechanotransduction (connective tissue) \\
15149463 & caldesman 1 isoform 4 & mechanotransduction of muscle and non-muscle cells \\
5453710 & LIM and SH3 protein 1 & intra-cellular and extra-cellular mechanotransduction \\
1485539842 & $\begin{array}{l}\text { deleted in malignant brain tumors 1 } \\
\text { isoform b (DMBT1) }\end{array}$ & may play role in suppressing tumor \\
7669492 & $\begin{array}{l}\text { glyceraldehyde-3-phosphate } \\
\text { dehydrogenase (GAPDH) }\end{array}$ & control of gene expression; DNA repair
\end{tabular}


these precursors of proteins or proteins were identified in the PVF of animal species. As many proteins have diversified functions, we put these 49 items in 5 groups (a-e). The number of each item follows that published in [26], for convenience of cross-examination. The function of the related proteins can be found in general from NCBI Gene report. For example, information can be obtain from the data of "APOA1 apolipoprotein A1 [Homo sapiens (human)]. Gene ID: 335, updated on 9-Jul-2016" for the Apolipoprotein A1. We will not put down such a similar and long list of references here.

If we follow our table, we find that the above-mentioned proteins plays general roles in (a) Life energy generation and related metabolisms; (b) Blood cells synthesis/regulation, iron ion transport, angiogenesis; (c) Interaction with key positive ions $\mathrm{Ca}^{2+}, \mathrm{Na}^{+}$, $\mathrm{K}^{+}, \mathrm{H}^{+}$, play roles involved in other signaling pathways; (d) Involved in body growth and development; (e) Cholesterol/hormone transport or synthesis, Vitamins transport, mechanotransduction, tumor suppression and DNA repair.

Obviously, these proteins, if so developed from the precursors, participate in majority of the major physiological functions. It is rather tempting to hypothesize that the PVs contain fluids with precursors of proteins for body development, life energy supply, and other key functions in physiological processes of the human body; note that the PVSs have been found in adult animal models and in the human placenta.

\subsection{Proposed Functions of the PVS at the Embryo}

In the chick embryo experiment, it was found that 7 - 8 hours after incubation, PV blast occurred; by 10 hours, the pre-PVs were formed; proto-PVs appeared. Then the PVS in the vitelline membrane of chick eggs appeared after 16 - 24 hours of incubation, whereas the extraembryonic (blood) vessels were formed 33 - 35 hours after incubation [19]. In view of the discovery of a large number of precursors of proteins responsible for the synthesis of extra-cellular matrix, bioenergy and various types of cells as briefly stated in the last section, we hypothesize that the first function of the PVS, in the embryo, is to generate the mesoderm, endoderm and the ectoderm, which are the three primary germ layers developed from the embryo. In particular, the cardiac cells, mesenchyme cells coelomocytes, skeletal cells, tubule of kidney cells, non-epithelial red blood cells, smooth muscle cells of the digestive system grow from the mesoderm. Hence, we anticipate that the PVS starts the initial generation process in the embryo development. Moreover, it has been reported in [27] that adrenaline and noradrenaline were found in the PVs on the surface of internal organs of the rabbits in the tissue samples. As explained in Section 1, it has been speculated in [3] that polar bodies are transformed into a system of vessels, namely the PVs, as an extraembryonic tissue. These vessels with ample "ingredients" have been speculated to control the oocyte maturation process, providing a possible picture on the role and destination of the polar bodies. We hypothesize that PVS forms the First Fluid of the circulation system. The water is obviously originated from the embryo water. The microcells (pre-stem cells) and proteins are developed while the oocyte grows. We consider that the PVS joins to the yet not well defined blood circulation system then, plus the extra-cellular-matrix which forms 
reticular fibers to support the blood vessels. We do not have enough information to sketch the complete PV circulation system at the embryonic stage at present. However, we are rather certain that once the blood vessels are formed, the head and spine emerge from the blood vessels, an established procedure in developmental biology. Suppose the basic structure of the embryonic fetus has been developed, and we can now jump to an adult body to discuss the second circulation system in the next section. Note that stem cells-like cells and catecholamine producing endocrine organ have been identified in PVSs of adult animals [27].

\section{The Second Fluid of the Five-Fluid Circulation System}

\subsection{Introduction}

The cardio-vasculature system is proposed to be the Second Fluid circulation system, which has already been extensively studied. We will only sketch briefly some relevant properties and highlight some features to be followed up in later sections, or the following papers of this series. In human, blood cells, glucose, proteins (majority is albumin), mineral ions, hormones, oxygen, carbon dioxide are suspended or dissolved in the blood plasma (of which around $92 \%$ by volume is water). Albumin is the main protein in plasma, and it functions to regulate the colloidal osmotic pressure of blood. Note that at any time about $84 \%$ of the whole blood volume of the body is circulating in the vessels, and $16 \%$ of blood is inside the heart and the lungs. Among the blood in the vessels, $64 \%$ is venous blood, $13 \%$ is inside arteries, whereas $7 \%$ is inside systemic arterioles and capillaries [28]. A blood vessel is composed of three layers-endothelial cells, smooth muscle cells and perivascular cells in larger blood vessels. These layers are separated by connective tissue layers and the outermost layer is the adventitia through which mechanical signals can be transmitted to the vessel. A capillary is much smaller and does not have smooth muscle cells (see details in Section 7). The wall of a venous vessel is thinner than that of an artery, and can hold more blood than an artery of the same type. Many veins have one-way valves for facilitating blood flow back to the heart. A common blood vessel disease, particular for women is the occurrence of varicose veins, commonly found at the back of legs. Such veins are enlarged veins caused by valve disorder/failure. The veins appear gnarled and engorged. Maintaining good blood circulation is of prime importance in health. When the small arteries in the hands and toes become narrow, poor blood circulation would result in these regions, and the Raynaud disease develops, usually in cold weather or under high stress.

Since the arteries do not contact the organs/organelles directly, there must be a medium to supply whatever is needed for the organs to function. The arteries decrease in their diameters as they are doing part of the life-keeping duty, necessarily the pressure (force per unit cross-section area) is also decreasing. Apart from such change in pressure due to change in cross-section area of the vessel, the blood flow speed must be decreasing also, because one (big) vessel is branched off to become many. Only in this way there is enough time for the arterial blood to transport the supportive "materials" to the organs at the site. Located between the arterioles and capillaries (diameter size of 
5 - 10 microns) are some muscle fibers, the precapillary sphincters, which can contract and thus regulate the amount of blood going through the capillary bed. In the return journey, the blood flows through the other "half" of the capillary bed (deep blue in diagrams of this paper and elsewhere, signifying the content of carbon dioxide) to join the smaller type of the venous vessels, i.e. the venules, which join the bigger venous vessels, with decreasing flow speed because the diameter of the transporting vessel is increasing in size. As the venous vessels have a total volume (when they are full of blood in the usual condition) much bigger than that of the artery vessels, $65 \%$ of the blood is retained in the venous vessels at any time. One sees bluish vessels near the skin surface, particular on the dorsal side of the hands. There are about 4.7 liters of blood in a human weighing about 68.2 kilograms/150 pounds, at one time.

There is a significant difference in the flow speed in arteries during systole and diastole. One usually uses the parameter called pulsatility index (PI), to calculate such a difference. $\mathrm{PI}=($ systole speed - diastole speed $) /($ mean speed at a site $)$, which is decreasing with increasing distance from the heart [29]. From the fluid dynamics point of view, perhaps an interesting comparison is to relate the total cross-section area diameter of one or more blood vessels at a particular region (where the vessels, artery or venous, are located) with the flow speed. The flow speed at the (i) aorta (with crosssectional area of $3-5 \mathrm{~cm}^{2}$ ) is about $40 \mathrm{~cm} / \mathrm{s}$, that at (ii) vena cavae inferior and superior (with cross-sectional area of $14 \mathrm{~cm}^{2}$ ) is $15 \mathrm{~cm} / \mathrm{s}$, whereas that at (iii) a capillary bed with a typical total cross-section area of $4500-6000 \mathrm{~cm}^{2}$, is $\sim 0.03 \mathrm{~cm} / \mathrm{s}$ [30] [31]. Note that the volume of blood passing through per second (found by simply multiplying the total cross-sectional area with the average flow speed), based on the above numbers, fall in the following ranges: (i) $120-200 \mathrm{~cm}^{3}$; (ii) $210 \mathrm{~cm}^{3}$; (iii) $135-180 \mathrm{~cm}^{3}$. These figures are of the same order of magnitude, but should not be equal, because there is water excreting outside the vessels to the "Third Fluid system - the interstitial fluid", as will be explained in Section 4, and represented schematically in Figure 2 there.

Normal blood plasma behaves like a Newtonian fluid, namely, whose viscous stress (due to the fluid flow) is linearly proportional to the local strain rate at every space point. The viscosity of normal human plasma at $37^{\circ} \mathrm{C}$ is about $1.1-1.3$ milli-Pascalsecond [32]. An increase of $5^{\circ} \mathrm{C}$ in temperature in the physiological range reduces plasma viscosity by about $10 \%$. In other words, the blood becomes less viscous at mild hyperthermia. This property is relevant to the flow fluency of blood to be discussed in a flowing paper.

\subsection{Blood Flow Rate Affects Remodeling of the Vessel Tissue through Change in Elastin/Collagen Ratio}

Collagen and elastin are two principle components of the blood vessel. Elastinolysis (which is inherited or acquired connective tissue disorder in which the skin becomes inelastic and become loose with folds) and collagenolysis (degradation of collagen) plays crucial roles in arterial remodeling. Since the mechanical properties of elastin and collagen fibers/fibrils are different, variation of their amounts readily leads to pathological states of the blood vessels and hence diseases related to abnormality in blood flow. 
CONNECTIVE TISSUE - INTERSTITIAL FLUID SUSTEM

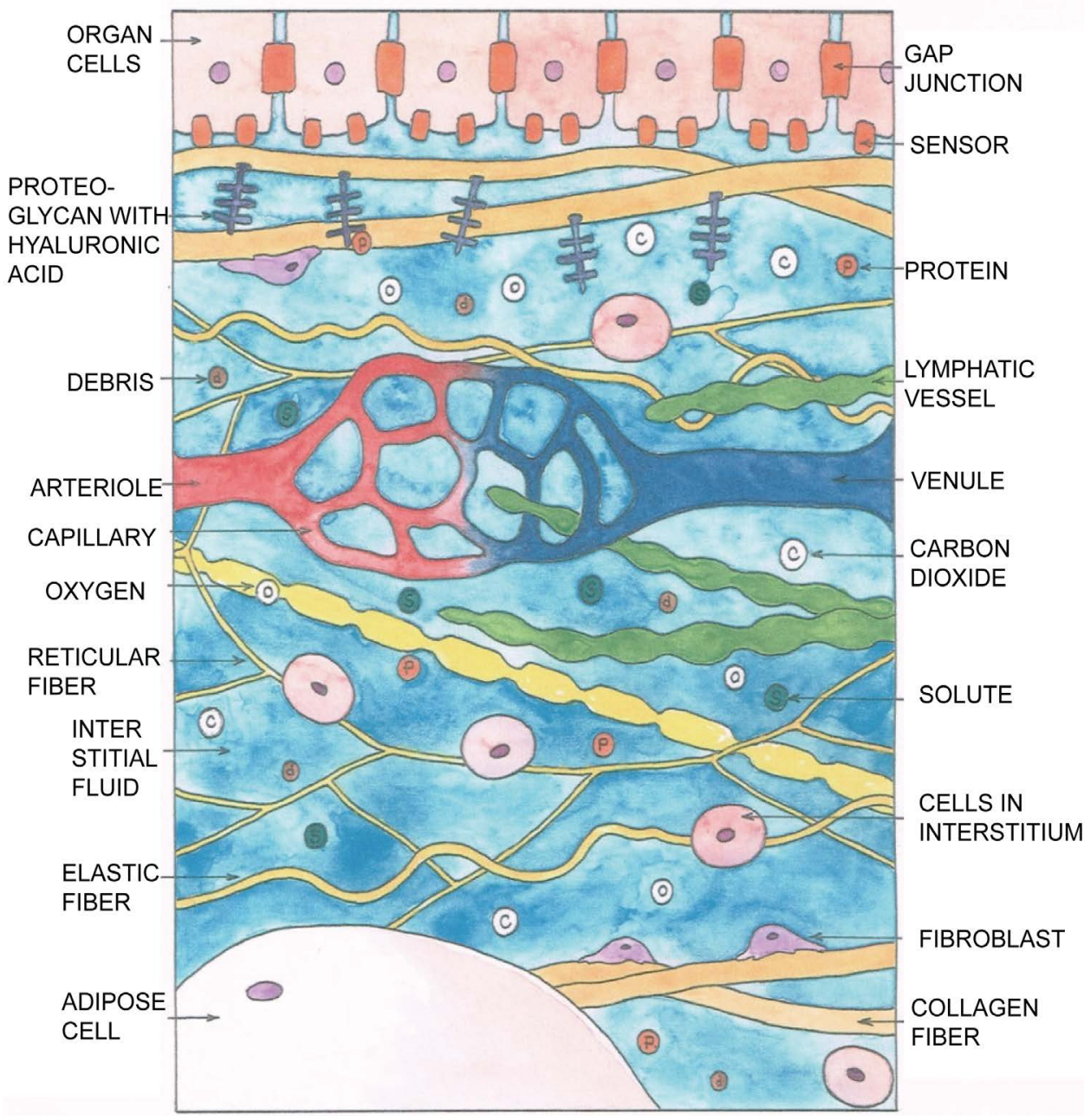

Figure 2. This diagram summarizes the basic constituents in the interstitium/(connective tissueinterstitial-fluid, or CTIF system), with the interstitial fluid playing important parts. The organ cells (orange) with gap junctions represent a certain group of cells in any part of the body. The sensors are simply integrins which can detect mechanical signals and send the message to the nucleus. The interstitium in general contains collagen fibers (light brown), elastic fiber (yellowish, with curvy shape at places), reticular fibers (also yellowish, straight thin lines) are all built of various class of collagen. Proteins, which are sent off from the blood circulation, are represented by small circles marked "p" (orange color). The tree like structure (purplish) represents proteoglycans to which hyaluronic acid is attached and water binds to such tree-like structure, making the major part of the ISF viscous. There is also free water flowing. The little circle marked " $\mathrm{s}$ " are solutes, including vitamins and other nutrients. The circles with "o" are oxygen molecules and those being marked " $\mathrm{c}$ " are carbon dioxide molecules. The cells are represented by the ellipse-shaped figures with their nuclei. They can be residence cells-mast cells which circulate in the CTIF system, pigment cells (in the skin), fibroblasts, and stem cells. The cells in transit are the white blood cells. The adipose cell is much bigger than other cells and is shown partly in the left corner there. The arteriole and venule vessels are connected by the capillary bed. A few of lymphatic vessels are shown schematically. The dark brown " $d$ " circles are wastes/debris from metabolism or immunity response. The back ground blue indicates the presence of the interstitial fluid which includes some free water. This diagram was painted by author PCWF. 
Due to difference in physiological demand in blood flow transportation, the ratio of elastin and collagen tend to decrease with increasing distance from the heart [33]. Note also that collagen has a faster turnover rate than elastin [34]. Collagen, and other components, of the ECM building the vessel cells and their surrounding ECM, are degraded by metalloproteinases (MMPs) and such degradation is regulated by inhibitors of metalloproteinases (TIMPs) [35] [36]. Studies on the elastin/collagen ratio in different types of blood vessels, with respect to blood flow rates would be useful to understand diseases related to abnormality in blood vessel remodeling. In [33] the relationship between blood flow rate and MMP/TIMP ratio in blood vessels is investigated. It has been remarked there that vessels with high blood flow rate showed a higher MMP-2 expression as compared to that with low blood flow rate and vice versa. The elastin/collagen ratio has been found to decrease from aorta, to carotid artery, femoral artery, femoral vein, but the blood flow rate has been found to increase from femoral vein, femoral artery, to carotid artery, then aorta (see Figure 3(a) \& Figure 3(b) of [33]). Passive tension vs stretch relationship for different vessel beds (as illustrated by aorta, carotid artery, vein) is shown in Figure 6 of [33]. For a fixed tension, the vena cava showed the minimum stretch, because this blood vessel has the minimum elastin and maximum amount of collagen, whereas the reverse is true for aorta, which has the maximum amount of elastin and minimum amount of collagen. In other words, the higher the elastin content in the tissue, the higher the compliance in that vessel. On the other hand, the result of Figure 5C in [33] suggests that increase in blood flow rate is associated with higher elastin-collagen ratio. Based on the above analysis, we propose that maneuver modality along the direction of blood flow on the veins (which appear superficially), would induce a higher blood flow rate. It is tempting to speculate that long term massage treatment might in turn induce a higher elastin-collagen ratio to be developed in the veins.

\subsection{Cardiomyocytes Beat Best on a Matrix with Elasticity Similar to the Heart}

Under the healthy state, myocardium, cardiomyocytes are attached to extracellular matrix (ECM) built of collagen fibers which have just the right degree of elasticity/ compliancy for actomyosin's action to pump the heart [37] [38] [39]. With proper blood flow rate, which is affected by the compliant property of the blood vessels, the pumping action is rhythmic with a frequency demanded by the physiological need. Clinically, myocardial infarct often leads to cardiac fibrotic rigidification, resulting in impairment of cardiac output [40].

In vitro investigation also shows that cardiomyocytes on rigid culture substrates demonstrate progressive loss of rhythmic beating [41]. The elasticity E of ECM provides cue for action of the heart cells during the stated mechanotransduction process.

In the study of [42], quail embryonic cardiomyocytes were plated onto collagen 1coated substrate, which mimics the extra-cellular-matrix (ECM). The maximum cell contraction and matrix contraction were recorded as the cardiomytocytes beat. The substrate elasticity E was systematically varied, so that pairs of data relating the maxi- 
mum contraction and $\mathrm{E}$ were obtained.

Since the cells are causing the contraction, cell strain $\varepsilon_{\text {cell }}$ always exceeds, or at most equal to the collagen matrix strain $\varepsilon_{\text {out }}$, i.e. $\varepsilon_{\text {cell }} \geq \varepsilon_{\text {out }}$. The strain sustained within the cell $\varepsilon_{\text {in }}$ during contraction is: $\varepsilon_{\text {in }}=\varepsilon_{\text {cell }}-\varepsilon_{\text {out }}$. On soft matrices $(\mathrm{E}<8 \mathrm{kPa}$ in the experiment with quail heart cells), cell strains have been transmitted almost completely to the ECM so that $\varepsilon_{\text {in }}$ is significantly smaller than $\varepsilon_{\text {out }}$. (see Figure 1C left of [42]) and there is very little contraction work done because there is no "rebounce". On very stiffest matrices, $\varepsilon_{\text {out }}$ is practically zero. Under this condition, the myosin-based contraction is fully sustained by the cell (see Figure 1C right of [42]), hyperactivating the stretch-sensitive proteins, but the cells cannot "move" the ECM. Again rhythmic contraction cannot occur. Under physiological condition, the heart cells and the ECM must play the "push and pull" game in synchrony to save the heart cells from overwork. Such a synchronized condition happens only when at an optimized elasticity $E^{\star}$ (in the quail experiment, $\mathrm{E}^{\star}=10$ kilo Pascal), at which $\varepsilon_{\text {in }}=\varepsilon_{\text {out }}$. Though embryonic cardiomyocytes were used in the experiment [42], we anticipate that the same result holds true for heart muscles of subjects. In practice, thus we must let the connective tissues around the heart to be maintained at the optimum condition. Such a result means that we should not allow the occurrence of inflammation or fibrosis on the collagen fibers around the chest region; even though abnormality of the elasticity $\mathrm{E}$ of the collagen fibers occurs somewhere away from the heart region, such abnormality could indirectly influence the E value of the cardiac ECM because mechanical force can be transmitted throughout the connective tissues of the fascia to far distances [43]. Thus allowing the heart to work with the best efficiency possible condition by relaxing the associated connective tissues would protect the heart and ensure the best possible blood flow.

\subsection{Circulation Function of the Emissary Veins}

Along the skull, there are many foramens through which vital neural and vascular structures pass. The emissary foramens on the skull allow the passage of emissary veins which connect the intracranial venous sinuses with extracranial veins of the scalp [44]. Under normal circumstances, blood flow rate through the emissary veins is slow, but the flow can be bi-directional. When the intracranial pressure becomes high, the emissary veins drain the cranial fluid outside the skull, reducing the pressure [45]. The emissary mastoid foramen is located at the mastoid site of the temporal bone, near to occipitomastoid suture (see Figure 1 of [46]). Based on analysis on the evolutionary aspects, we learn that the size of the mastoid foramen and the associated veins has become larger in human. It has been verified that the mastoid emissary vein connects the sigmoid sinus, which drains into the vertebral venous plexus when a human is in the upright position, but drains into the internal jugular vein when the subject is in the supine position [47]. It is also found that infection or tumors originated in the face and infratemporal fossa can spread through the mastoid emissary veins as they enter into the cranial region. Thus we suggest, as a matter of principle, that massage using Bian stone or otherwise, along the superficial emissary veins as shown in Section 7 would 
reduce the risk of infection in the "dangerous region" in modern medicine. To clear the fluid from internal jugular vein, we therefore consider that, with the subject in supine position, massage along directions of several nerve routes (which are adjacent to the veins emerging on the superficial layer of the face before joining the internal jugular vein) might be helpful to the process of brain fluid clearance, an issue to be discussed in details in Sections 7 and 8.

The second and third foramen of interest to us is the parietal foramen, which is located $2-5 \mathrm{~cm}$ anterior to the external occipital protuberance [48] and the parietal emissary vein(s) is located laterally to the sagittal suture, at the boundary between the posterior third and middle third of this suture. This foramen can occur bilaterally, unilaterally or completely absent, depending on the ossification process of the anterior fonticulus in individuals. The parietal foramen allows passage of the emissary vein (at that site) to connect the superficial veins on the scalp and the superior sagittal sinus inside the skull. This foramen is also considered as "dangerous foramen" for spreading infection to the sinuses of the dura matter inside the brain. We also propose that massaging the superficial veins connected to the parietal emissary veins against direction flow into the skull with the subject in upright position could well be a non-invasive measure to avoid the stated risk of infection.

The sphenoidal emissary foramen (with the sphenoidal emissary vein) allows the passage of an emissary vein that connects the pterygoid venous plexus to the cavernous sinus.

As the superficial occipital veins join the occipital emissary vein, on route to the deep cervical vein, then the external jugular vein, we propose to massage, starting from the occipital foramen site, in a downwards direction when the subject is in upright position. Some people are short of some emissary veins, and we think that is a good sign because of the dangerous scenario of the two-way blood flow along emissary veins [49].

\section{Interstitial Fluid as the Third Fluid of the Five-Fluid Circulation System}

\subsection{A Brief Sketch of the Interstitium}

In a multi-cellular organism, after a (fermented) cell has completed its first mitosis into two and then more cells, a system of communication must have developed from the mesoderm to cater for the coordination of the function of a group of cells in a controlled environment, and morphogenic development, for the survival and growth of the organism as a whole. Such a communication system must allow the exchange of various forms of energy and materials (like exchange of biomolecules via osmosis, diffusion) for both biophysical and biochemical interactions. Thus all cell groups have extracellular matrices (ECM) which are built of collagen fibers that can communicate, in particular mechanically, with the integrins of the cell membrane of the organ cells. There are also elastic fibers to provide the connective tissues with elastic property and there are reticular fibers which help to support organs/organelles in position. Carbohydrate-protein complexes are present to inflate the fibrous network to keep the body in shape, also al- 
lowing diffusion of small molecules in and out of the tissue through the interstitial fluid (ISF) [43] [50]. These protein complexes have two main classes (i) Proteoglycans (PG) with its subclasses Aggrecan, Glycosaminoglycan (GAG) and others. Note that hyaluronan is the most abundant and ubiquitous member of the GAGs [51]. The proteoglycan proteins, to which hyaluronan is attached, form negatively charged long chains. Hydronium ions together with layer of water are then bound to the hyaluronan, forming a thick interstitial fluid in the interstitium, called the ground substance. (ii) Glycoproteins having subclasses such as Fibronectin, and Tenuscin. These two classes (i) and (ii) of proteins provide a potential bridge between the connective tissue matrix and the cells adjacent/within the interstitium. There are "residence cells" in the interstitium with almost constant populations: fibroblasts, mast cells, adipocytes, melanocytes. There are also "cells in transit" which migrate from the blood when in need: monocytes, macrophages, lymphocytes, eosinophils, and plasma cells. They are mainly engaged in immunity duties.

\subsection{Reasons for the Emergence of the Interstitial Fluid System as the Third Fluid in the Circulation System}

We know that arterial blood vessels are abundant in the body. The organs of the body are composed of specific cells (such as muscle cells, cardiomyocytes, hepatic cells, neurons,...) which must obtain, in addition to oxygen molecules, water, nutrients, signaling molecules (such as amino acids, sugar, solutes, specific proteins, hormones) to carry out physiological functions. The cells in the body are degraded and replaced by new cells (apart from the neurons in the brain) continuously. During infections and repair processes, the organs/organelles have to get help from immunity cells, Matrix metalloproteinases (MMPs), which are calcium-dependent zinc-containing endopeptidases to degrade the damaged collagen (fibrils/fibers) of various classes. Other enzymes and proteins may also be needed during such infections/disorders and repairs. Stem cells, fibroblasts of various pheno-types, and other cells (such as white blood cells) also participate in the remodeling/repair processes. Thus, during physiological or pathological conditions, part or all of the mentioned "necessary components" must be transported to the target sites-tissues, or organs/organelles. As the artery vessels, including capillaries, are not directly "joined" to the cells of organs, other means must transport all the stated components to the target(s). Therefore, the interstitial fluid forms naturally the Third Fluid to carry out such transportation duties; this transportation includes transportation of information - the interstitium with interstitial fluid (ISF) provides a platform for efficient carriage of signaling peptides/proteins. Moreover, flow of the ISF provides a shear force to collagen fibers which in turn transmit the associated mechanical force to the integrins or other receptors in the cell membranes to trigger off mechanotransduction processes.

This particular fluid has to flow without the confinement of tubes. The medium of transportation is water, as mentioned in Section 1. More specifically, there are hydrophilic and hydrophobic bio-molecules, small and large, inside the body. Therefore wa- 
ter must serve also as a medium of transportation of these molecules. In the blood circulation system, the lipid drops (which are typical examples of hydrophobic bio- molecules) are enclosed by a spherical structure (due to the hydrophobic nature) with a single lipid layer, called chylomicron. The chylomicrons transport fat from the blood stream to the liver, (via the ISF for a small part of the journey) where the lipid is broken down to form cholesterol, to be used to generate energy. Nutrients/bio-molecules having ionic property form solutes in water. The positive ions of water are bound to the hyaluronic acid structure, which is negatively charged and attached to the proteoglycans; these are non-collagen proteins in the intersitium. A very viscous fluid is formed to impede the flow speed, so that the tissues/organs can receive their parcels $\left(\mathrm{O}_{2}\right.$ and nutrients etc) from the mailman. In summary, the ISF is doing very important work all the while, though the average flow speed is very slow, being only $\sim 10$ micron per second or even less, dependent on sites. The total volume of ISF passing through the body each day is not small-a human body treats about 2 - 4 liters per day. At 37 degrees $\mathrm{C}$, whereas the specific gravities of plasma, lymph, whole blood, and synovial fluid are very close to that of water-unity, the viscosities of these fluids are respectively 1.2 , 1.5 - 2.2, $3.0-3.84,10-10^{4}$ milli-Pascal, covering a wide range [52]. In Figure 2, the basic constituents of the interstitium with the ISF are schematically presented.

\subsection{Basic Functions, and Some Physical Properties of the Interstitial Fluid}

In addition to the well-known function of providing transport of nourishment, oxygen to organs, interstitial flow also induces blood and lymphatic capillary morphogenesis (see evidence in in vitro experiments in [53] [54] [55] [56] and lymphatic regeneration in vivo [57]), upkeeps the physiological activity of chondrocytes and osteocytes [58] [59] [60], initiates fibroblast to differentiate [61] [62], and triggers smooth muscle cells to produce cytokines [63]. The existence of suitable interstitial fluid pressure is critical for ocular health [64]. Even during embryonic development, cilia in motor protein drives convective ISF flow to pattern the early stage of life [65].

Up to $20 \%$ of the body's mass is made up of interstitial fluid [66]. During inflammation and acute edema, the flow speeds are greatly enhanced [67] [68]. The ISF flow is drained by the lymphatic system which processes several liters (up to 8 liters) of lymph per day [69], with around $2 / 3$ of the amount coming from the liver and intestines [66]. The ISF transport is not a one-way process. Note that oxygen, and plasma have leaked out of the blood capillaries arising from the hydrostatic and osmotic pressure differences i.e. the Starling forces [70] [71]. The plasma and carbon dioxide are returned to the blood circulation via the ISF.

Mass transport within the interstitium is critical for the maintenance of interstitial cells. Solute molecules (nutrients for the viability of cells) which are transported within the interstitium space between blood capillaries, have a range of size from several hundred microns in soft tissue [70] [72] [73] to several millimeters in the case of cartilage [59]. Many events take place in ISF transport [74]. Cells actively secrete proteins, bind 
and "absorb" (internalize) proteins, release proteases which can free the proteins that are bound to the ECM etc.

The composition and structure of the interstitium systems vary in different parts of the body for very good physiological reasons. The connective tissues, together with the help of the interstitial fluid, give mechanical support to cell groups/organs, based on which mechanical properties are specified. Normal leakage of plasma from blood vessels (due to Starling forces stated before) is the main source of fluid in the interstitium of most soft tissues. Therefore the interstitial fluid contains around $40 \%$ of the protein concentration of plasma, but with slightly different ions compositions for various reasons [66].

The magnitude of the ISF pressure (ISFP) at a location is influenced by many factors, such as exercise, blood pressure, tissue metabolism, hydration, ECM composition, and cell density at that location [75]. With regards to relation between ISFP and exercise, we would remark also that the interstitial flow in cartilage of joints is driven by time-dependent forces (compressing the tissues) resulting from motion such as walking [59] [76]. The ISFP, as enhanced during exercise, helps to transport nutrients, wastes, and proteins between chondrocytes (which are embedded in the cartilage). Remark that blood capillaries are at a distance because there is basically no blood circulation through the cartilage. In addition to passive causes, cells in the interstitium also play crucial active roles, such as maintaining tension in the ECM (in a $\beta 1$ integrin-dependent manner) to regulate ISFP [77]. The magnitudes of ISFPs in some examples of tissues are listed in [78]. Pressure gradients between the interstitium and lymphatic fluid cause ISF to flow into the lymphatic system in general. In passing, we note that using radioactive tracers, there is experimental evidence that the interstitial fluid flow tracks in animal models and human are correlated with Traditional Chinese Medicine Meridians [43].

\subsection{Interstial Fluid Flow Guides Lymphangiogenesis as an Introduction to Another Fluid in the Circulation System}

Blood angiogenesis occurs in embryonic development, wound healing, and tumor growth initiated by a number of polypeptide growth factors such as VEGF-A and angiopoietin-2 [79]. The main physiological driving force for blood angiogenesis is the demand of oxygen, which is directly correlated with the primary function of the blood circulation system. In fact, growth factors such as VEGF-A and erythropoietin are expressed under the condition of hypoxia, inducing an oxygen-sensitive transcription factor called factor-I, to initiate the early stage of angiogenesis [80]. On the other hand, the primary function of the lymphatic system is to maintain interstitial fluid balance by providing lymphatic clearance of interstitial fluid and macromolecules. The consequence is that osmotic and hydrostatic gradients from blood capillaries through the interstitium are sustained, giving condition for interstitial protein transport, which is an important physiological process. The above consideration suggests that interstitial fluid flow is very likely to play a role in lymphangiogenesis. In an experimental model de- 
veloped in [81], a 2-mm-wide circumferential annulus of skin was removed (around half way) from the mouse tail, leaving the underlying bone, muscle, major blood vessels, and tendons intact (see Figure 1 of [81]). Examination of normal tail skin of mouse model, Atomic Force Microscopy (AFM) showed a regular hexagonal network of lymphatic vessels in the skin (see particularly Figure 1a of [81]). There are many subcutaneous blood vessels, but the interstitial fluid and lymphatic vessels are within the region of the skin being removed. Therefore blood flow to the tail remains uninterrupted, but the lymphatic network and the flow of interstitial fluid out of the tail tip are completely interrupted by the above surgery procedure. Such a condition, if untreated, would lead to significant edema of the tail [82]. However, in the experiment of [81], when a collagen dermal equivalent (CDE) was inserted into the site of the removed skin to provide path for fluid flow, no edema occurred (see Figure 1b through 1d of [81]). These authors used AFM to track lymph flow pathways (either as fluid channels or lymphatic vessels) within the $\mathrm{CDE}$ for a time interval of 60 days after the procedure. After at least 10 days, fluid channels were observed to be formed, bridging the distal and proximal portions of the lymphatic system; finally, those channels were replaced by an organized hexagonal network of lymphatic capillaries. This is concrete evidence supporting the proposal that interstitial fluid flow guides lymphangiogenesis.

\section{The Fourth Fluid-A Mixture of the Cerebrospinal Fluid and the Brain Interstitial Fluid}

\subsection{An Updated Concept of Cerebrospinal Fluid Generation}

Classically, CSF is known to be continuously secreted with a pulsatile manner by the four choroid plexus (CPs) (via the choroidal epithelium, a part of the blood-CSF barrier (BCSFB)) of the two lateral, third, and fourth ventricles. The CSF flows into the subarachnoid space (SAS) through the foramina of Luschka and the foramen of Magendie. The arterial blood vessel in the choroid plexus exits fluid around the vessel; but the vessel is surrounded by a layer of fenestrated endothelial cells so that only very small molecules can "leak out" from the blood vessel to the surrounding fluid. This fluid is further surrounded by an epithelial layer of cells with tight junctions, called ventricular ependymal. The above mentioned "two-layer structure" forms the blood-CSF barrier so that the CSF does not contain large proteins or harmful macro-molecules. Referring to Figure 3, the capillaries of the choroid plexus (part of it is enclosed by the dotted line) excrete water, glucose, oxygen, vitamins and ions into the mentioned ventricles and the fluid with its constituents contributes the main part of the CSF in the brain. For immunity purposes, macrophages and lymphocytes migrate from the blood and pass through the vessel wall and then the small openings among the ependymal layer, to the ventricles "outside". The brain produces around $480 \mathrm{~mL}$ of cerebrospinal fluid per day in a normal adult. With constant reabsorption, there is only 125 to $150 \mathrm{~mL}$ present at any one time. It is estimated that about $80 \%$ of the fluid in volume is contained in the subarachnoid space in the cranium and spinal cord. The rest is circulating in the ventricles [83]. 


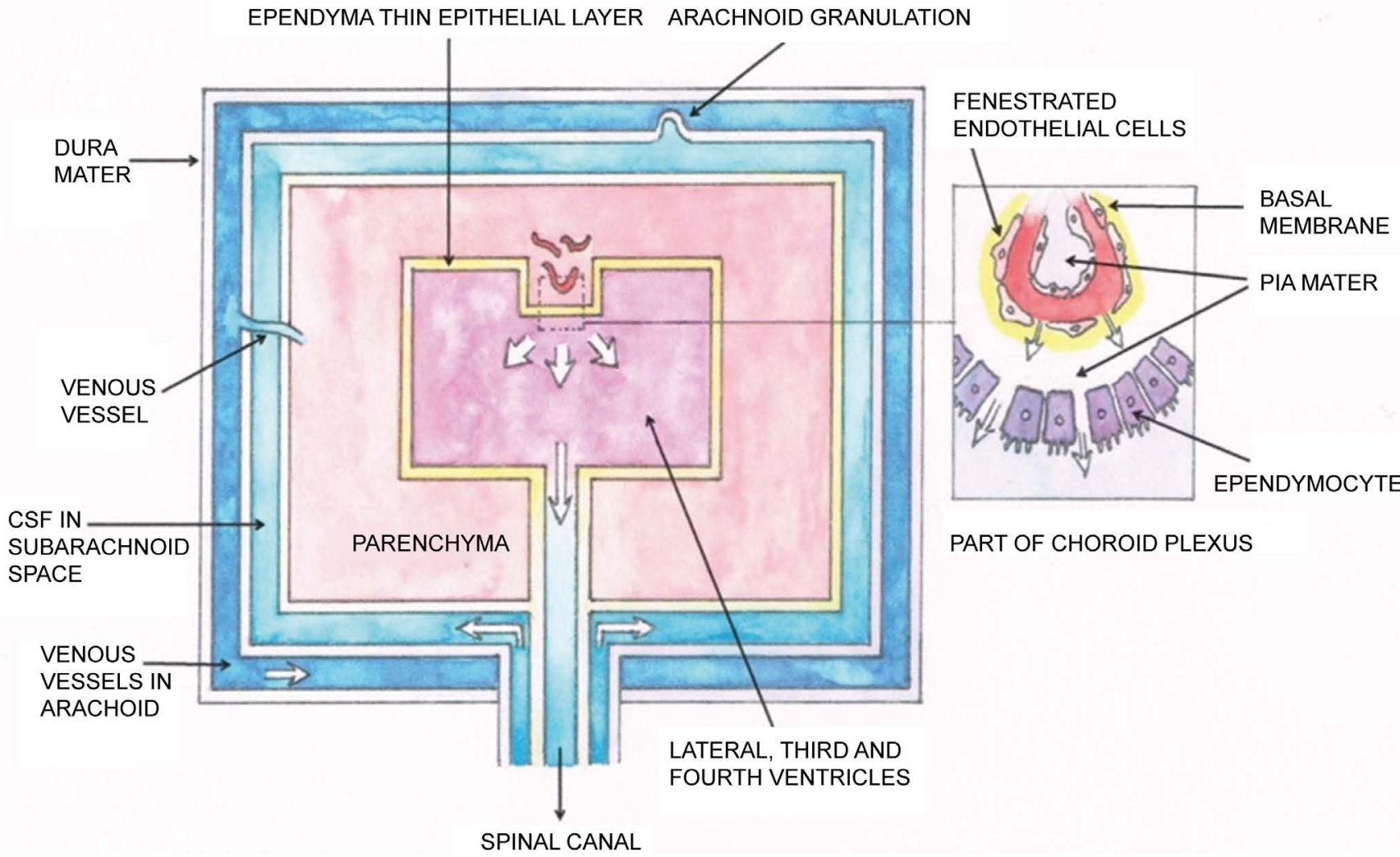

Figure 3. Schematic representation of the blood-CSF barrier and the classical model of brain drainage via vein vessels. The ependymal thin epithelial layer (yellowish color) encloses the lateral, third and fourth ventricles of the brain. The cells of this layer are called ependymocytes, joined together by tight junctions, but have some very small opening ( $<50$ microns). The capillaries of the choroid plexus (part of it is enclosed by the dotted line) excrete water, glucose, oxygen, vitamins and ions into the mentioned ventricles and contributes the main part of the CSF in the brain. The capillary is enclosed by fenestrated endothelial cells, which allow small particles to go through. For immunity purples, macrophages and lymphocytes migrate from the blood and pass through the vessel wall and then the small openings among the ependymal layer, to the ventricles "outside". The stated passage of this CSF is indicated by the white arrows. The CSF passes down to the end of the canal of the spinal cord and return to the sub-arachnoid space as shown by the white arrows. Following the pumping action of the heart, together with contribution of the arteries along the spinal region as described above, there is a resonance of the ventricles and the spinal column, and the characteristics of the fluid pulsation have been detected by MRI study [85]. Figure 3 is modified from Figure 1 of [86]. This diagram was painted by author PCWF.

There are granulations from the subarachnoid space into the superior sagittal sinus (venous vessel), so that the CSF flows back to the blood circulation. The blood circulation in and out of the skull is well known and will not be discussed here. The CSF was considered to be a fluid isolated from the brain intersititial fluid. So this is the general picture of the CSF up to a few years ago. Let us turn first to a new addition to the generation of the CSF discovered only a few years ago.

A model of the human blood vasculature system including all main systemic arteries (i.e. including the circle of Willis in the brain) coupled to a heart model has been developed [84]. The one-dimensional (1-D) form of the momentum and (fluid flow) continuity equations were solved numerically to obtain pressures and flow velocities throughout the systemic arterial tree. Parameters specifying the arterial dimensions were obtained from previous 1-D models plus extended calculations. Flow characteris- 
tics in large systemic arteries of young subjects were measured with MRI, whereas cerebral flow features were obtained from ultrasound Doppler analysis, and fluid pressures at various locations were measured with tonometry. Employing a similar methodology, a schematic representation of the arterial tree consists of 120 vessel segments contributing to the generation of CSF in the spinal cord and the brain region is depicted in Figure 2A-C of [85]. Connection between this cardio-vascular system and the CSF system was constructed by a transfer function which is specified by a number of parameters: spinal volumetric (mechanical) compliance (as measured by the elastance coefficient $\mathrm{Ke}$ in units of $\mathrm{ml} /[\mathrm{mmHg}$ height]), fluid pressure, flow speed and flow waveform in the connected system [85]. These parameters were compared with the in vivo measured data of the stated combined system, giving results which support the suggestion that certain amount of CSF is supplied by the fluid of the blood circulation from systemic arteries plus cranial arteries. In particular, the CSF flow \& CSF pressure were calculated, with input parameters from measurements, as functions of the spinal compliance (Ke, from flexible to stiff), taking the distance from the first cervical disc $\mathrm{C} 1$ as a parameter. It was noted that the CSF pressure wave reflection was greater at the caudal end of the spinal subarachnoid space (SSS) when the spine was more flexible (i.e. $\mathrm{Ke}=0.04)$.

Here we refer the reader to Figure 3 which summarizes schematically the circulation of CSF in the brain and central canal of the spinal canal.

\subsection{CSF Follows Special Pathways to Mix with BISF in the Brain Parenchyma}

We have briefly analyzed certain basic characteristics of the CSF. On the other hand, the neurons of the brain, as other organs of the body, are nourished by the interstitial fluid, which is different from the CSF. In fact, the interstitial fluid (ISF) exists in all connective tissues - including that surrounding the parenchymal cells of the brain and spinal canal. The water, nutrients in the form of solutes, plus proteins and some cells leave the blood vasculature and enter the interstitium as interstitial fluid, described in Section 4. The structure of the blood brain barrier (BBB) is well known. In brief, the arterial capillary in the parenchyma (neurons and astrocytes mainly) is surround by a layer of endothelial cells with tight junctions, which are further enclosed by a structure of basal lamina. There are also pericytes in this lamina layer. The external layer is embedded by endfeet of astrocytes; there are however small cleft (around 20-nm wide) or in layman term, "leak spaces" in between the endfeet. Thus the fluid from a capillary in the brain parenchyma could exit first to the lamina layer and then pass through the "leak spaces" to reach the brain cells. We call this brain interstitial fluid as BISF. The $\mathrm{BBB}$, which regulates the water, nutrients, proteins and the amount of BISF that can reach the brain cells, and thus controlling the brain function [87].

More technically, the BBB and blood-CSF barriers regulate molecular exchange at the interfaces between the blood and the neural tissue or its fluid spaces with the following specific functions: (A) Ionic homeostasis-restricting the (para-cellular) move- 
ment of small ions, with the result of regulating blood-brain ionic traffic. (B) Restriction of small molecule permeation. (C) Specific transport of desirable small molecules needed by the brain. (D) Restriction and regulation of large molecular traffic. (E) Separation of peripheral and central neurotransmitter pools to avoid cross-talk between [88].

For at least a decade, the (classical) CSF was considered to be reabsorbed into the blood stream either through (i) the arachnoid granulations of the dura sinuses, or (ii) by emerging out of the cranial cavity along cranial nerve sheathes to the cervical lymphatics [89] [90]. However, the brain is a heavy-duty organ and large amount of wastes is generated continuously by the brain. Moreover, it is hard to believe that the relatively small amount of fluid carried out of the skull by processes (i) and (ii) could balance the water generated at the choroid plexus and SAS of the spinal canal. Therefore biomedical scientists tried hard to find pathways that had not been discovered in the past decade to carry fluid with soluble plus insoluble wastes out of the brain.

Tracers of different sizes were injected into the ventricular region or cisterna magna of mice models, and movement of the tracers were assessed using imaging technique in the parenchyma in [91]. Their findings were: (i) Small amount of the two small sized tracers was observed to cross ependyma of the lateral and third ventricles after $30 \mathrm{~min}$ of continuous infusion. (ii) After injection intracisternally of $40 \mathrm{kD}$ tracers (FITC-d40), the fluid with tracers flew along the sheaths of arterial vessels in the sub-arachnoid space into the parenchyma. (iii) The amount of tracers found in the brain is inversely proportional their sizes. (iv) The authors inferred that these tracers followed two pathways along one vessel: (a) the basement membrane (BM) between the vascular endothelial and the smooth muscle cell layers; (b) the sheath between the adventitia and the astrocyte endfeet (see Figure 4). The movement was inferred in [90] to be caused by arterial pulsation. We, however, consider that in general fluid flows from a high pressure point to a lower one, and the injection at the cisterna magna would certainly create a pressure gradient to drive the fluid (together with tracers) initially. This phenomenon was called the arterial influx (of CSF) to mix with BISF. The mixture with tracers was observed to follow the sheaths of venous vessels and drain into the SAS. At the meantime, we modify the diagram in [91] to illustrate schematically the mixing of the CSF and BISF.

Although the tracers mentioned in Figure 4 were injected with fluid at the cisterna magna, yet under physiological condition, since there is a driving force on the CSF originated from pulsation of blood flow analyzed in Section (5.1), we anticipate that the same mixing process goes on continuously. The mixing rate may be different from that found in in vivo animal study [91]. The mixing process was confirmed with MRI using the in vivo rat model in 2013 [92]. As the brain is a heavy-duty organ, a lot of wastes, both soluble and in soluble exist in the mixture CSF-BISF, which is the Fourth Fluid of our model. In particular, there is ample evidence that $\beta$-Amyloid and $\tau$-protein have been found to be deposited inside the brains of patients suffering from Alzheimer, Parkinson and other neurodegenerative diseases [93]. For many decades, whereas the 


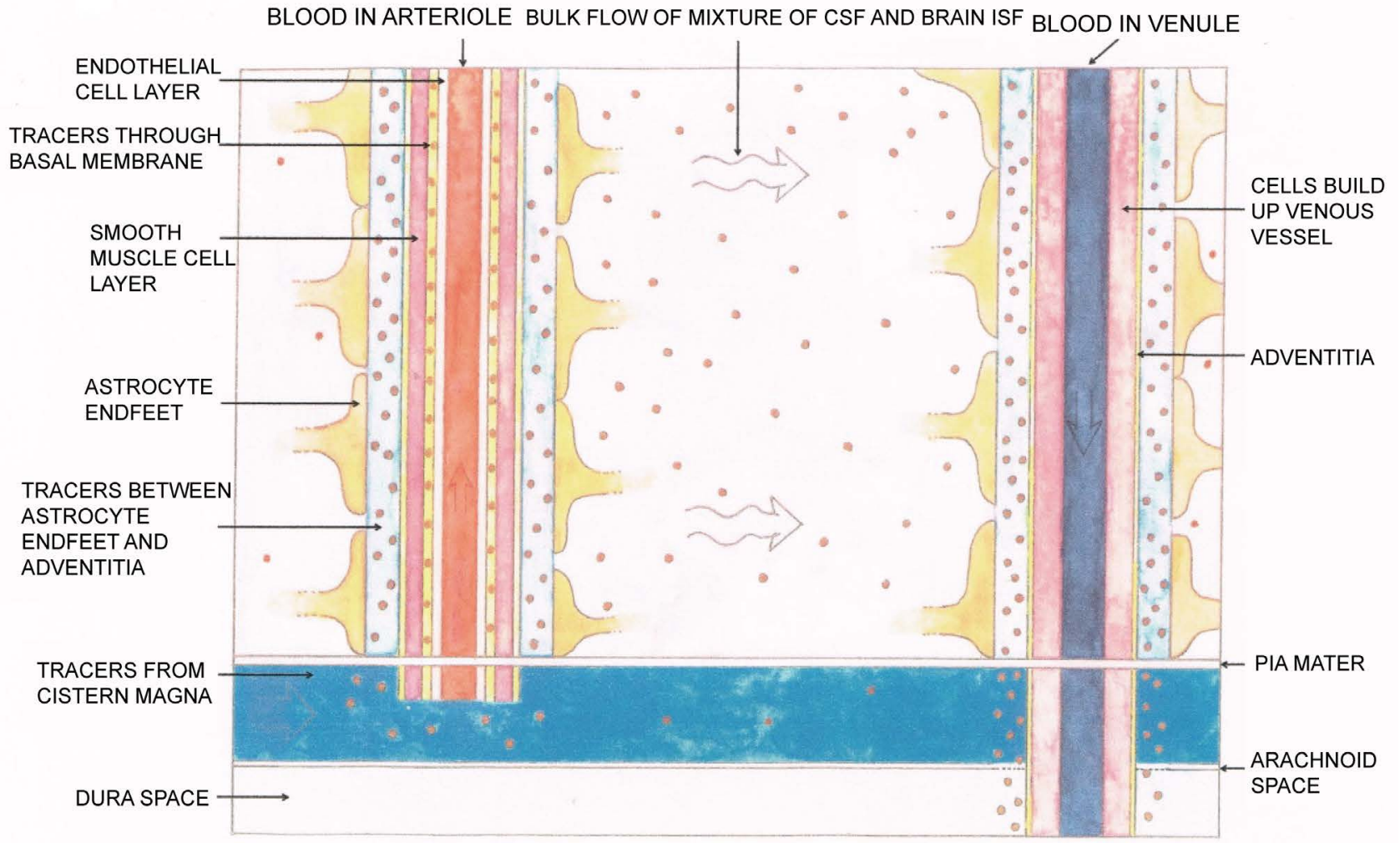

Figure 4. Experiment demonstrating the mixing of CSF and BISF. In [91], tracers were injected at the cistern magna so that they would pass through the subarachnoid space. It was found that the tracers were carried by the fluid up via two pathways; (i) along the sheath between the external arteriole wall (i.e. adventitia) and the astrocyte endfeet; (ii) along the basement membrane next to the endothelial cells. This influx occurs for arterial vessels, but not for veins. The tracers then were carried by the ISF bulb flow though the parenchyma, as indicated by the two wavy arrows. The yellowish pink parts represent parts of the astrocyte endfeet and the pink region represents the brain cortex. The fluid mixture was then carried through the sheath between the astrocyte endfeet and the adventitia (light yellow) of the venule (on the right side of the diagram), flowing downward with the tracers through a pia mater layer, the subarachnoid space, the arachnoid space with dura mater and then outside the skull. This diagram, which was painted by author PCWF, is modified from Figure 2 of [91]. In this diagram, the arterial vessel has penetrated into the subarachnoid space from somewhere not shown in the diagram and turn up to pass across a pia layer into the brain, whereas the venous vessel pass through the dura space, and other boundary layers to exit the skull.

lymphatic system is found practically to be associated with blood vessels, the absence of the vital clearance system inside the brain had been a mystery. We will therefore provide a comprehensive analysis of the extra-cranial lymphatic system in Section 6 first, and then review the important discovery related to the stated mystery published only around one year ago in Section 7.

\section{Lymph as the Fifth Fluid}

\subsection{How and When Is the Lymphatic System Developed}

The theory of lymphatic development has not been well established even up to now. Since lymphatics have been observed to sprout from the murine cardinal veins [94], many accept the theory stating that the embryonic lymphatics develop as isolated lymphatic endothelial cell sacs, which then develop into the lymphatic endothelial tubes 
[95]. One might therefore consider that the main lymphatic vessels develop from the grand veins, whereas all the other lymphatics develop independently from the venous system by a process of canalization of the connective tissues clefts [96]. There is evidence that the lymphatic muscle cells are originated from mesenchymal progenitors [97]. There is also evidence that electrical action potentials trigger lymphatic smooth muscle contractions and vice versa [98]. In fact, the spontaneous and intrinsic nature/origin of these contractions suggests that each action potential/(rhythmic contraction) is preceded by a pacemaker event, like cardiac contraction (see Figure 2 of [96]). Here we speculate that the Primo Vasculature System participates in supporting the function of the lymphatic system, based on the fact that the PVs have been found to be inside and in the vicinity lymph vessels.

\subsection{Structure of the Lymphatic System}

The ISF contains both some useful proteins and some debris, plus "unwanted cells" like cancer cells and bacteria. It is precisely the function of the lymphatic system to treat about 3 liters of ISF and return it back to the blood system, along directions towards the heart. Hence the lymphatic system is not a closed circulating system, but the constituents in this fluid, the lymph, are different from that of the blood, ISF, and BISF and are different at different parts of the body. The lymphatic system plays important roles in immunity, and is not as simple as many would have imagined; in fact there are several organs, called lymphoids attached to the lymph vessels, to participate in carrying out the physiological duty just mentioned. Some relevant features of these lymphoids are briefly sketched below.

Major Lymphoid organs include (i) Bone marrow where production of $\mathrm{T}$ lymphocytes and maturation of B lymphocytes take place. (ii) Thymus where thymocytes are matured into $\mathrm{T}$ lymphocytes. Peripheral lymphoid organs can be classified into (a) Lymph nodes which are spaced along lymphatic vessels, form clusters in the chest, neck, pelvis, axilla, inguinal region, and near the blood vessels of the intestines. There are around five to six hundred lymph nodes in the human body. (b) Spleen contains over half of the body's monocytes, and is a center of activity of the mononuclear phagocyte system. It produces lymphocytes and is considered to be a very large lymph node [99] [100].

\subsection{Entry of the Interstitial Fluid with Its Components into the Lymphatic System through Initial Lymphatics and then the Collecting Vessels}

\section{Introduction to entry of the interstitial fluid into the lymphatic system}

A rough estimation shows that several hundred million people suffer from edema due to disorders of the lymphatic drainage in global scale [101]. To understand lymphatic flow is therefore of great importance in health care and related medical treatment. Let us start from the entry of the ISF into the "capillaries" of lymphatic vessels. Interstitial fluid and cells, particulates/macromolecules enter the lymphatic system 
through the lymphatic capillaries, also known as initial lymphatics, or terminal lymphatics [102]. This "entrance small tube" is built of a single layer of flattened endothelial cells usually without a smooth muscle component. However, the over-lapping endothelial cells with connective tissue structures have hairy detectors (see Figure 5). These detectors are pushed by the flowing interstitial fluid, and the ISF can flow inside the duct as indicated by the white arrows, bringing with it the debris (circle in brown), protein(orange) from the interstitium, and cells (lymphocytes and other cells, represented by ellipsoid with nucleus). The interstitial fluid flows through overlapping edges of neighboring endothelial cells (microvalves). In contrast to the structure of a blood capillary, a lymphatic capillary has a thin wall with a wide lumen, irregular structure; the wall does not contain pericytes and a basement membrane. Following the flow, the lymph is then drained into a collecting lymphatic vessel [103], which is surrounded

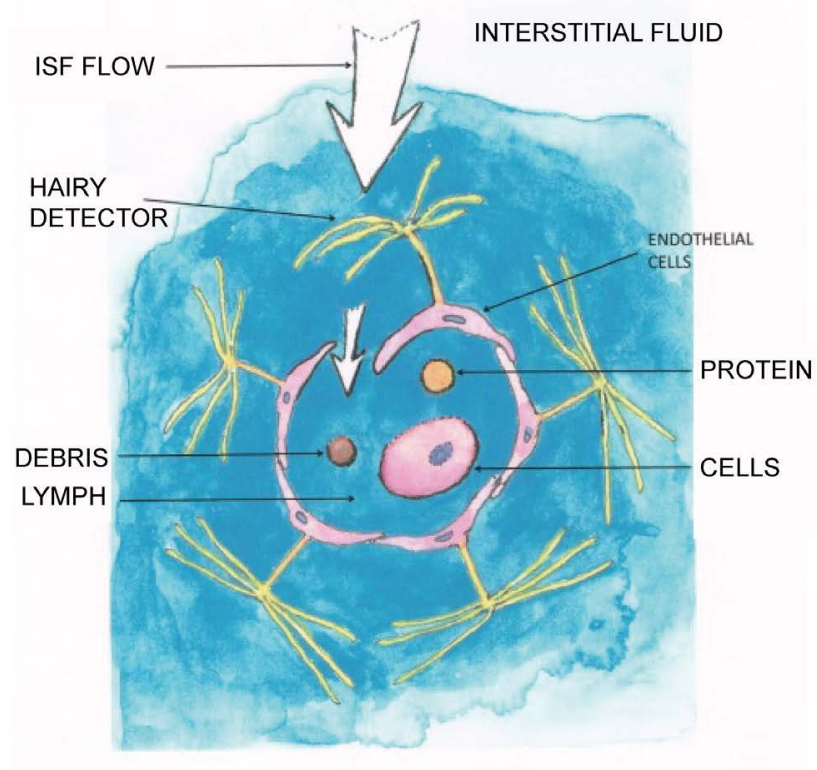

(a)

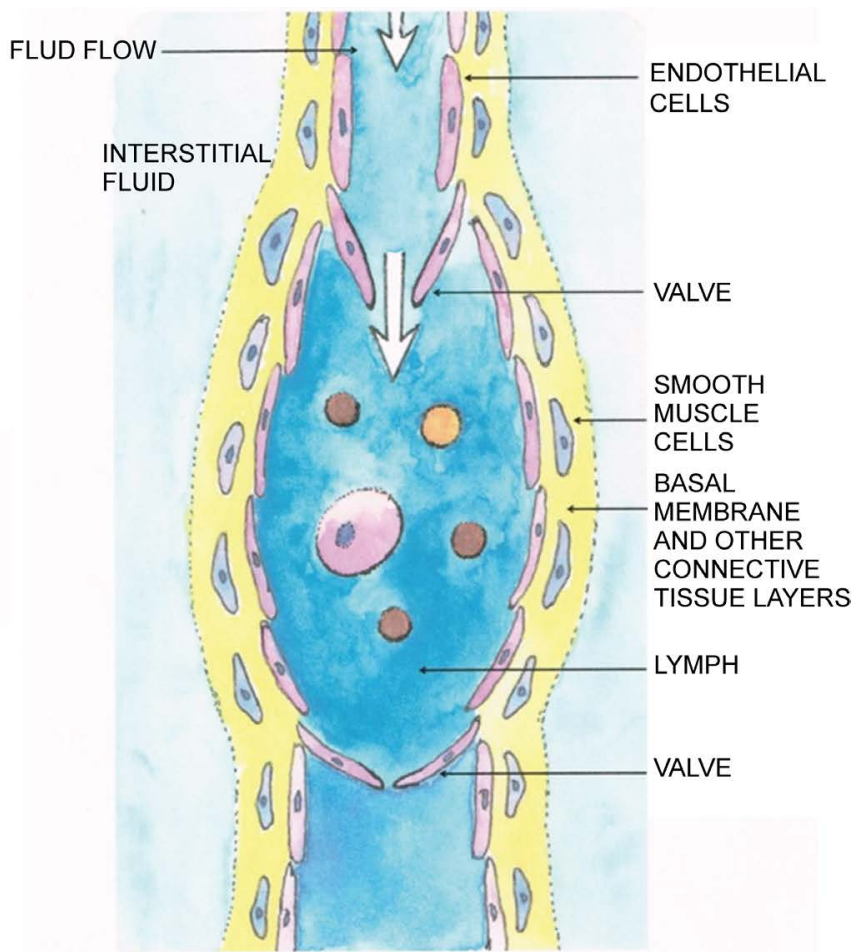

(b)

Figure 5. (a) Cross-section of an initiative lymphatic vessel with hairy detector. This type of vessel is built of over-lapping endothelial cells with connective tissue (omitted in the diagram for simplicity). When the hairy detector is pushed by the flowing interstitial fluid, the ISF can flow into the duct as indicated by the white arrows, bringing with it the debris (circle in brown), protein (orange) from the interstitium, and cells (lymphocytes and other cells, represented by ellipsoid with nucleus).With very low interstitial fluid pressure, the "flaps" are closed. Therefore fluent ISF flow will "open" the initiative lymphatic duct to trigger off the immunity response. (b) A basic unit of collecting duct-lymphangion. The endothelial cells are painted in light purple, which is surrounded by basal membrane, similar to that in a blood vessel. The bluish purple structure with nucleus represents the smooth muscle and para-vascular cells. There are two valves at both ends, to provide one-way traffic for the lymph flow. When the lymph fluid flows in, the lymphangion bulges a little because the fluid pressure is increased. The yellowish region represents the connective tissue (collagen) - and the outer part is similar to the adventitia in blood vessel. The smooth muscle cells are not so strong as that of the blood vessels and extrinsic propulsion is often needed. Figure 5(a) is modified from Figure 1 of [103] and Figure 5(b) is modified from reference ([102] Figure 2 D). These diagrams were painted by author PCWF. 
by a basement membrane, a layer of smooth muscle cells (SMC) or pericytes (see Figure 5, showing a basic unit of a collecting vessel, a lymphangion). These collecting lymph vessels contain luminal valves in order to prevent the back-flow. The one-way transport lymphatic system plays a key role in the maintenance of normal interstitial fluid volume and protein concentration. The immune competent cells also enter the lymph vessels and do their duties in the lymphatic nodes.

\subsection{Intrinsic Propulsion of Fluid by the Lymph Pump}

Even the ISF can enter the lymphatic initial duct, a propulsion mechanism is needed to drive the fluid flow. Historically, to look for the origin of such propulsion force driving lymph to flow through the peripheral to the major lymph duct (such as the thoracic duct), and then to the venous system, a series of experiments with unanaesthetized sheep as model were carried out half a century ago (see e.g. [104]).

Using a fistula system in the sheep model to study the lymph flow characteristics, it was found that lymph flow was intermittent with a well-defined rhythm that was unrelated to muscle movements, unrelated to respiration (except in the case of the thoracic duct for obvious reason based on anatomical structure).

The pulsatile pressures recorded from the various lymphatics ranged from 1 to 25 $\mathrm{mm} \mathrm{Hg}$, with pulse frequencies from 1 to $30 / \mathrm{min}$. The magnitude \& pulse rate of the pressure pulses increased as the lymph flow rate increased. When the various lymphatic cannulas (in the fistula system) were clamped to prevent lymph flow, the pressures in the lymphatics increased (reaching a high pressure up to $60 \mathrm{~mm} \mathrm{Hg}$ ) and the frequency of contractions also increased.

From experiment such as that just mentioned, we learn that one important driving force to cause lymph flow is the intrinsic contractile activity of the active lymph pump (composed of a series of lymphangions) whose function has been considered to be similar to the cardiac cycling action [105] [106]. Note also that there are branching patterns of lymphatic system, making the flow profile in lymphatics even more complicated. In general there are no valves at the junctures of lymphatic branch points. Thus the contractile activity around the junctures is asymmetric and significant retrograde flow could well result. Hence it is difficult to predict the general direction of lymph flow in a local region unless the detailed structure of the vessel system, together with the nature and locations of valves are known. However, the early experimental result in [107] already showed rather convincingly that intrinsic rhythmic contractions of the valved lymphatic vessels are mainly responsible for the propulsion of lymph from the periphery to the thoracic duct, with the function to control the removal of tissue fluid at a rate proportional to its rate of formation. Thus the intrinsic contraction mechanism has been considered to be established.

\subsection{Extrinsic Forces Can Affect the Flow Characteristics}

\subsubsection{Definition of Extrinsic Propulsion Forces on Lymph Flow}

There are several extrinsic forces that can reinforce or impede lymph flow, which has 
been caused by forces external to the lymph vessel, in a complicated manner: (i) The pulsation of the nearby blood vessels would aid lymph flow. (ii) Motion of skeletal muscles or tissues around the lymphatic vessels during exercise would squeeze the lymphatic vessels and aid fluid flow. However, it was reported long ago that sustained skeletal muscle activity would decrease lymph flow [107] [108] because outflow resistance of peripheral lymphatics would be increased. We consider such a result is expected because there is evidence that pulsatile pressure on the lymphatic vessels would enhance lymph flow; but compression with too large a frequency or too large a force would impede the lymphangion pulsations. (iii) The suction effects of respiration. Most of the time these forces help to move lymph centripetally. (iv) Note also that there are branching patterns of lymphatic system affecting the flow profile driven by both the intrinsic and extrinsic forces. Now the term "extrinsic" lymph pump is meant to be a combination all extra-lymphatic forces which can influence (in general meaning enhancement) lymph flow. The origin of these forces (which can be applied artificially) is not connected with active contractions of muscle cells in the lymphatic vessel wall.

\subsubsection{Evidence of the Effect of Blood Vessel Pulsations on Lymph Pressure of Large Lymph Vessels}

Since many branches of the artery and lymphatic vessels run roughly parallel to each other for long distances, intuitively one expects that movements from the great arterial trunks are imparted to the larger collecting lymphatics. In a number of studies, it has been inferred that the continual pulsatile motion of the lymphatic vessels are at least in part originated from the pulsation of the blood circulation. On the other hand, in the neck, where the thoracic duct is in close relation to large pulsating veins, venous pulsations are considered to be transmitted to the lymph also (in particular, in the subclavian triangle area). Using dog's model, the rhythmic intralymphatic pressure change in the supradiaphragmatic and cervical thoracic duct was investigated [109]. In both areas lymphatic pulses were found to be transmitted from the nearby large arteries. In the neck region, venous pulsations were also shown to be transmitted to the lymph in a similar manner. However, these pulsations were shown to propagate for only a few millimeters. In conclusion to this aspect, the blood circulation pulsation may trigger the pulsation of the lymph to certain extent. On the other hand, for smaller vessels in the peripheral regions, further study is needed to confirm such features relating to "transmitting of pulses between nearby small vessels".

\subsection{Physiological Functions of the Lymphatic System and the Causes of Lymphedema [96]}

The main function of lymphatic smooth muscle cells is to maintain tissue fluid homeostasis, by contracting rhythmically to allow the lymphatic system to remove the suitable amount of interstitial fluid, proteins plus lipid drops from the interstitial space [110]. The lymph flow drives the immunity cells, antigens, and fat to the lymph nodes whereby immunity function, fat transportation (eventually to be metabolized at the right place) are carried out. As explained in Section 4, clearance of debris of the ISF is 
important to health, implying lymphatic malfunction can be very series. Lymphatic dysfunction can be triggered by (i) gene mutations, or (ii) damage to the lymph vessels or valves. Tissue inflammation arising from external insult, or blood vessel leakage may lead to excessive storage of interstitial fluid and hence excessive increase in ISF pressure, resulting (ii) above. The overall consequence of lymphatic dysfunction is impaired immunity, chronic edema in the interstitium and accumulation of subcutaneous fat.

Colloid proteins and water are constantly filtrated from the arterial side of the capillary bed into the interstitium (red arrows in Figure 1 of [102]). Under physiological condition, majority of the filtrate is collected by the lymphatic capillaries (green arrows in Figure 1 of [102]) whereas a small amount of the fluid is reabsorbed into the venous capillaries (blue arrows in Figure 1 of [102]). However, during inflammation, a much larger amount of filtrate enters into the interstititum. If there is obstruction of the veins due to venous thrombosis or venous insufficiency, the reabsorption process will be impeded. Further, if certain parts of the lymphatic drainage system are dysfunctional, edema would result. Therefore, lymphedema is now defined as tissue swelling due to a low output failure of the lymphatics, leading to accumulation of (macromolecule-rich) interstitial fluid in the interstitium. If the primary blockage of lymph flow occurs in the lymph conducting pathways inside the lymph vessels or lymph nodes, the phenomenon is called primary lymphedema. If the stated obstructing of lymph flow occurs elsewhere, the disease is called secondary lymphedema [111]. In both of these two situations, lymphatic smooth muscle dysfunction is the main cause of the pathology. Lymphatic filariasis is the most common cause of lymphedema in general, affecting over 100 million people world-wide. The most common symptoms of such a disease are lymphangitis, dilated lymphatics, and decreased lymphatic contractile function, leading to weakening of lymphatic contractile activity [111].

\subsection{Proper Exercise or Massage Enhances Lymph Flow}

Radioactively labelled serum albumin was injected bilaterally into the vastus lateralis muscles of eight subjects $(n=16)$. The scintographic method was employed in [112] to measure the total clearance of the radioactive tracer, but this method cannot distinguish between convective removal via the lymphatics and dissipative transport via blood capillaries. It was noted, however, in the clearance of interstitially injected albumin, the convective transport of lymphatics removes at least $75 \%$ of the interstitial albumin [113]. The subjects performed 100 submaximal contractions exercise in $10 \mathrm{~min}$ as (i) dynamic knee extensions (CONS), (ii) isometric contractions with the knees at full extension (IMExt), or (iii) isometric contractions with knees fixed at 90 deg angle flexion (IMFlex). The exercises were separated by 65 min periods in supine rest.

Reference [112] reported that there was a consistent three- to sixfold increase in the clearance rates due to muscle contractions by subjects performing three types of knee exercise stated above. Subjects: Eight healthy men (25 - 55 years) volunteered for the study.

Evidence of massage enhances skin lymph flow 
Recirculation of the extravascular protein molecules, colloids back to the blood stream is an important function of lymphatic system.

Using 99mTc-colloid (TCK17 Cis) as a tracer, the lymph flow clearance in the skin was analyzed in anaesthetized pigs, in response to massage as a stimulus. It was found that lymph flow was slow and labile; at the capillary level, lymph propulsion was considered to be generated mainly by tissue movement. Gentle local massage applied continuously around (but not over the injection site) was performed employing a hand-held massager. Not only the clearance rate of the massaged sites was faster, the clearance rate of the non-massaged areas was also enhanced. The authors interpreted such as result as due to systemic effect or a spinal-reflex effect, leading to increase of lymph flow on the contra-lateralside [114].

\section{The Glymphatic System}

\subsection{Endeavor to Understand Pathways for Lymphatic Drainage of CSF along Sheaths of Nerves and Spinal Cord up to the Early 2000s}

Throughout the several decades before 2000s, there were debates about whether there was direct connection between the CSF and nasal lymphatics. Scientists attempted to find out the mechanism of such clearance [115] [116]. In particular, drainage via the neighborhood of facial nerves was therefore investigated. There were two models to explain the proposed drainage.

A simplified anatomical picture of olfactory nerves and cribriform plate, arachnoid space of the head is shown in Figure 6(a). In the first preposition there was the "open cuff model" (as Model B in Figure 6(b)) in which the perineural sheath cells were assumed to "disappear distal" to the cribriform plate, giving space for the CSF to flow into the interstitial space (outside the skull) where it is absorbed by the initial lymphatics in the olfactory and respiratory submucosa [115]. There was also the "closed cuff model", assuming the perineural space as a roughly spread out sag (cul de sac) so that the lymphatic vessels could fuse with the perineural cells, getting direct access to CSF which flows along the olfactory nerve (as Model A in Fig. 6 (C)). There were very good attempts for around the past two decades to distinguish which model was realistic. However, more recent data (in rat and other animal models, using microfilm as a contrast medium) suggests rather, that CSF-BISF could move directly from the subarachnoid space into submucosal lymphatics that emerge at the level of the cribriform plate, implying the clearance process is more efficient than that represented by Figure 6(C) [117] [118] [119] [120] [121]. During that time, the function of the glymphatic system (specified in later sub-sections) was not clearly understood.

Among those experiments, an important lymphatic CSF-BISF clearance pathway is the olfactory route leading to cervical lymphatic vessels. However, there is accumulating evidence there are other nerves, such as the trigeminal, acoustic, hypoglossal and vagus nerves [120] which may conduct CSF-BISF extra-cranially. Later, lymphatic vessels were found in vascularized human corneas [122]. 
(a)

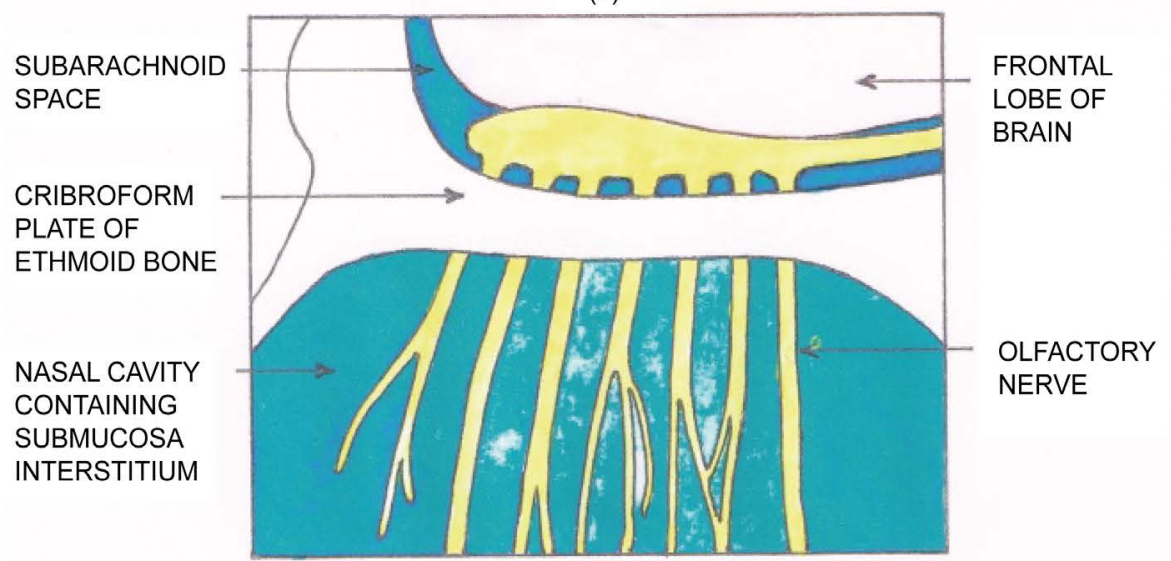

(b)

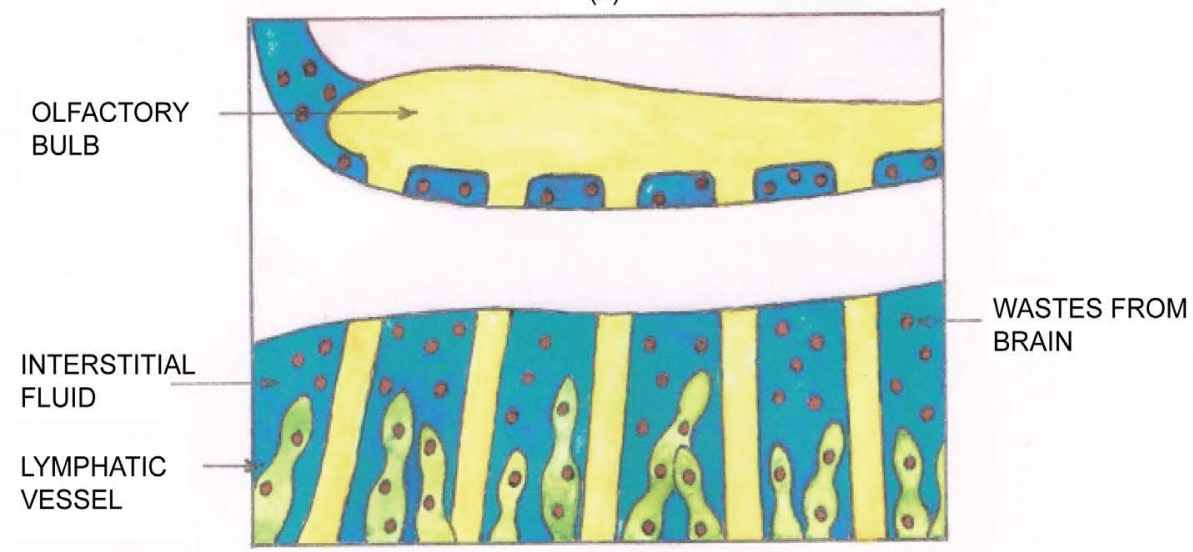

(c)

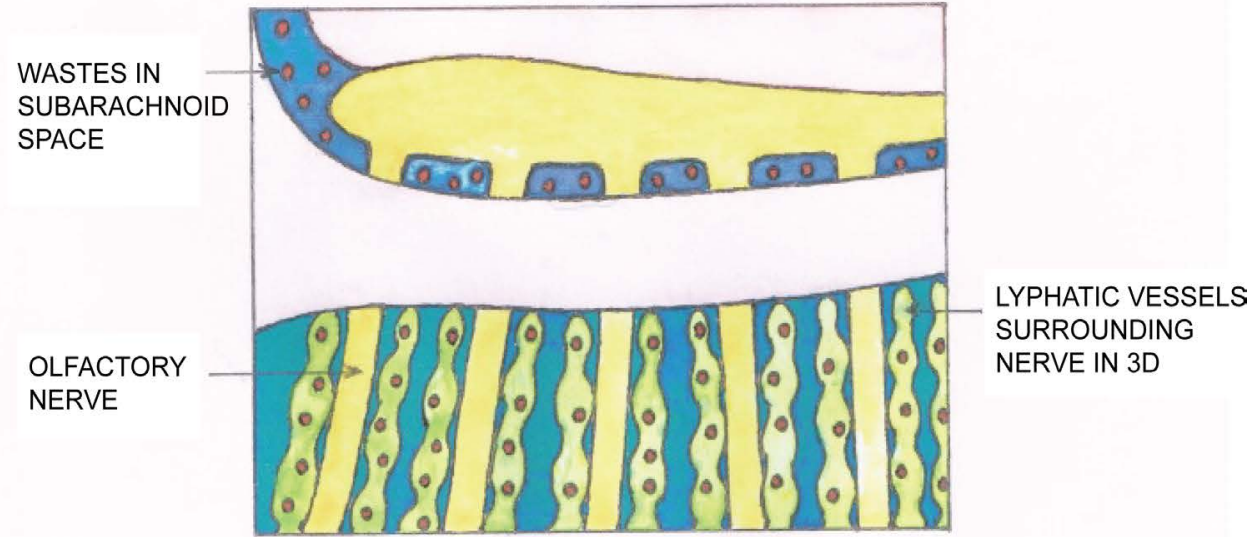

Figure 6. (a) Simplified anatomical picture of olfactory nerves and cribriform plate, arachnoid space of the head. (b) A model in which the wastes have to enter the submucosa interstitium below the cribriform plate, and join the ISF there. Lymphatic vessels are present in the submucosa region and the wastes are carried by ISF and enter the lymph system as in many parts of the body. (c) Shows the model where the lymphatic vessels are very close or directly below the cribriform plate, so that in a three dimension picture, the lymphatic vessels "enclose" or "form a collar-like" structure around each olfactory nerve. The debris/wastes from the subarachnoid space are driven by fluid pressure to enter the initial lymphatic vessels and are eventually drained through the lymphatic nodes in the facial and neck regions. Figures 6(a)-(c) were painted by author PCWF. 
One possible location for lymphatic CSF-BISF absorption that has been ignored generally is the dura of the spinal cord itself. In rats, lymphatics exist around the wall of the sagittal sinus, in the regions of the confluence of sinuses in the neighborhood of the mesothelial cells of the subdural spaces and close to the vasculature of the dura tissues [123].

India ink infused into the ventricles or cisterna magna of rabbits has been found to emerge around spinal nerve roots as well as in the lumbar para-aortic lymph nodes in rats [124] [125]. Also, in monkeys, lymphatic vessels have been observed in spinal epidural tissues [126]. Since there is no direct evidence supporting direct spinal CSF-BISFlymph connections so far, it appears that CSF-BISF from the spinal subarachnoid compartment first passes into the epidural tissues from which absorption takes place into blind ending lymphatic vessels ([116] Figures 1E-1F). Quantitatively, studies employing sheep model showed that the relative proportion of CSF absorption by the spinal compartment amounts to about $25 \%$ of total CSF-BISF clearance [127]. Thus, though there was evidence of lymphatic clearance of CSF-BISF in the dura mater of the spinal cord, the mechanism of clearance of the brain fluid inside the skull was a mystery for decades. Note that in the above studies, CSF was considered as an isolated fluid; i.e. the mixing of CSF and BISF was not understood then.

\subsection{Evidence of Drainage of Solute and Insoluble Fluorescent Microspheres through the Basal Membrane of the Arterial Vessels to the Subarachnoid Space Based on Mouse Model Study- Beginning to Discover the Glymphatic System}

Using the (healthy) mouse model, 3-kDa soluble dextran, ovalbumin (40 kDa), and insoluble particulate fluospheres $(0.02 \mathrm{~mm}$ and $1.0 \mathrm{~mm}$ in diameter) were injected into the grey matter of the corpus striatum (caudate putamen) of the brain. Imaging and immunocytochemistry analysis were carried out after 5 min to 7 days. This is set (i) of model. In Figure 7(a) (adapted from Figure 1 of [128]) is a schematic representation of a longitudinal section of a capillary joined to an artery vessel passing through the parenchymal region to the subarachnoid space. The inner most layer of endothelial cells (pink) is surrounded by a basement membrane, outside of which is a layer of smooth muscle cells. The external elastic membrane encloses this layer of cells. There are also perivascular cells in an artery vessel. The vasculature system has a layer of pia mater. According to the result of [128], the solute (together with fluid), as indicated by brown arrows, enters the basement membrane and the smooth muscle cells, and flow outside the parenchyma region, at least to the subarachnoid space. If the artery is inside the subarachnoid space (SAS) for a distance, these solutes may enter the vein vessels and drain via the classical pathway. If the artery vessel passes outside the skull, we anticipate that the solutes will enter the ISF in the facial region and be drained via the lymphatic initial vessels there. Experimental result in [128] also suggests that the insoluble tracers (brown small circles) passes along the connective tissues (not shown in above diagram for simplicity) which might be considered as part of the basal membrane between the 


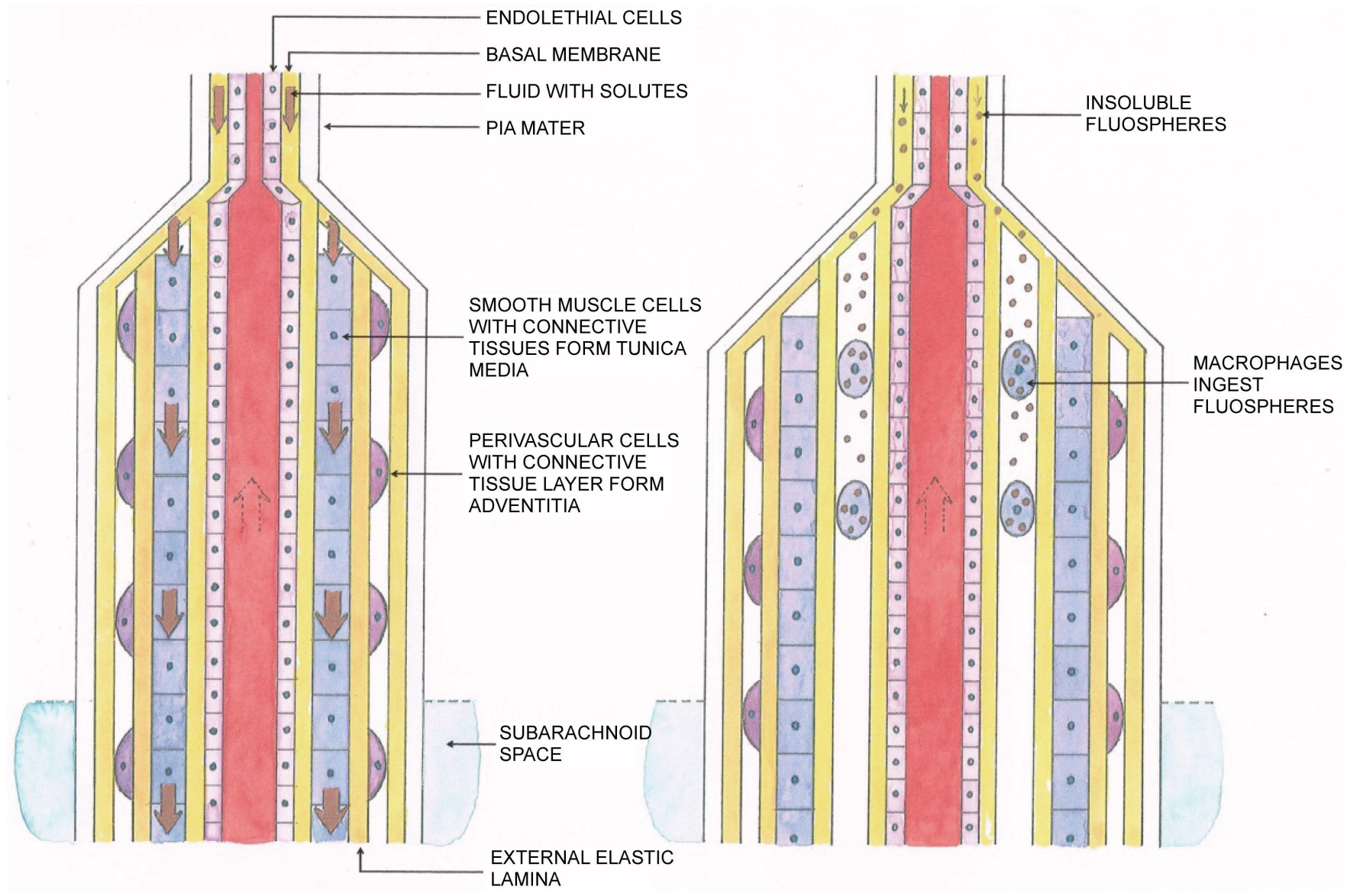

(a)

(b)

Figure 7. (a) Schematic representation of a longitudinal section of a capillary joined to an artery vessel passing through the parenchymal region to the subarachnoid space. The inner most layer of endothelial cells (pink) is surrounded by a basement membrane, outside of which is a layer of smooth muscle cells which are wrapped around by connective tissues (together forming the tunica medium) which can be considered to be extension of the basal membrane. The external elastic membrane encloses this layer of cells. There are also perivascular cells together with connective tissue layer, forming the adventitia. The vasculature system in the brain has a thin layer of pia mater (light grey color). The dotted arrow indicates the blood flow direction and the solid brown arrows represent the pathways of the solutes which are drained either to the arachnoid space and might be drained to regions outside the skull, depending on where the arterial vessel passes through. The connective tissues around the smooth muscle cells are not shown here for simplicity. (b) Experimental result suggests that the insoluble tracers (brown small circles) pass along the connective tissues (not shown in above diagram for simplicity) which might be considered as part of the basal membrane between the smooth muscle cells in the tunica media. The basement membrane is split into two layers, and the insoluble fluospheres (brown circles) are brought by the fluid through such a space, and are engulfed by the macrophages (also stained in the experiment) migrated from the blood vessel. Diagrams above are modified by painting (author PCWF) from Figure 3 and Figure 4 of [128]. Note that arterial blood vessels release macrophages and lymphocytes (see (Section 3)).

smooth muscle cells in the tunica media. The basement membrane is split into two layers, and the insoluble fluospheres (brown circles) are brought by the fluid through such a space, and are engulfed by the macrophages migrated from the blood vessel (see Figure $7(\mathrm{~b})$ ). The very recent evidence of the existence of lymph vessels (which will be called the glymphatic vessels) in the SAS provides a direct route to drain these solutes; this aspect will be discussed in details in the next subsection. In set (ii) model of [128], mice were suffering from cardiac arrest. It was found that the stated peri-vascular solute 
drainage did not occur. Such a result can be taken to suggest that rhythmic propulsion of blood through the arterial vessels might take part to induce the passage of the brain fluid through the basal membrane of the vessel.

Experimental results reported in [128] also suggest that the basement membrane (being built of collagen fibers with loose structure) is split into two membrane layers, and the (insoluble) particles are brought by the fluid through such a space. During the past several years, there are reports from different groups reporting similar type of peri/ para-vasculature drainage from the brain. Numerical analysis of motion of particles in a fluid in motions supports that idea that the wastes are more readily carried along the peri-arterial space, rather than carried by diffusion in the parenchyma [129].

\subsection{The Glymphatic System (Existence of Lymphatic Vessels inside the Skull) Confirmed in Mice Model}

In [130] the authors used a transgenic mice model that expresses the green fluorescent protein under the promoter of Proxl, a master control gene in lymphatic development. Through imaging the expression pattern of the Proxl gene in glymphatic endothelial cells, the detailed structure and morphology of dura glymphatic vessels in the model were revealed clearly. We use the term glymphatic vessels to signify the lymphatic vessels inside and at the boundary of the skull bone. In Figure 1 of [130], white arrowheads denote glymphatic vessels, yellow arrow heads denote the exit sites where the newly found glymphatic vessels leave the skull. To their surprise, an extensive network of glymphatic vessels was found in the meninges underlying the skull bones (Figures 1A-1J of [130]). In sagittal planes of the inner skull, glymphatic vessels were observed to run down toward the base of the skull along the transverse sinus, the sigmoid sinus, the retroglenoid vein, the rostral rhinal vein, and the major branches of the middle and anterior meningeal arteries. Moreover, during their experimentation, the authors reported visualization of glymphatic vessels in the vicinity of several nerves-optic, trigeminal, glossopharyngeal, vagus, and accessory-at sites where these nerves exit the skull. In particular, glymphatic vessels could be observed also in the dura lining of the cribriform plate, where blood vessels and olfactory nerves passed from the skull into the nasal mucosa. It was noted that only the glymphatic vessels at the base of the skull contained valves; we consider such a setting is a natural protective measure for clearance, in order to ensure the lymph flows outside, but not into, the skull.

Moreover, tracers were injected into the parenchyma region of the brain where BISF carries nutrients into the neurons and receives wastes. While it is difficult to trace the transport of wastes all along the pathways for obvious technical reason, using ligation technique, it was demonstrated in [130] that (extra-cranial) ISF was not drained to the superficial cervical node, but rather to the deep cervical node of the lymphatic system. Further, with a transgenic mouse model expressing complete aplasia of the dura glymphatic vessels, macromolecule clearance from the dura region into the deep cervical lymph nodes was abrogated, while the fluid content was not affected. Based on this particular result, we suggest that the BISF could well flow out of the brain through the 
sheath of the blood vessels (in particular the veins). If the dura glymph vessels are well developed, the macromolecules are transported to the deep cervical nodes. In Figure 8, we therefore draw glymphatic vessels in the dura layer outside the arachnoid layer. Outside the dura space is the skull bone [131] [132].

We would also note that there is evidence that lymphatic vessels were found in the cornea of human eye over one decade ago [122]. Upon discovery of the glymphatic system, it is of practical importance to search for the condition under which the clearance system is most effective - this is discussed in the following sub-section.

\subsection{On Drainage during Sleep}

The removal of potentially toxic biomolecules that accumulate during normal physiological function is an issue of health and the process of aging. By the age of 85 , the risk of Alzheimer's disease (AD) is estimated to be about 50\% [133].

In the brain, metabolic protein $\beta$-Amyloid has quite many functions such as cholesterol transport, activation of kinases, as antioxidant, as a transcription factor, and participating in protection from microbes. Clearance of this protein is known to be via (i) uptake by microglial phagocytosis; (ii) receptor-mediated transport across the blood

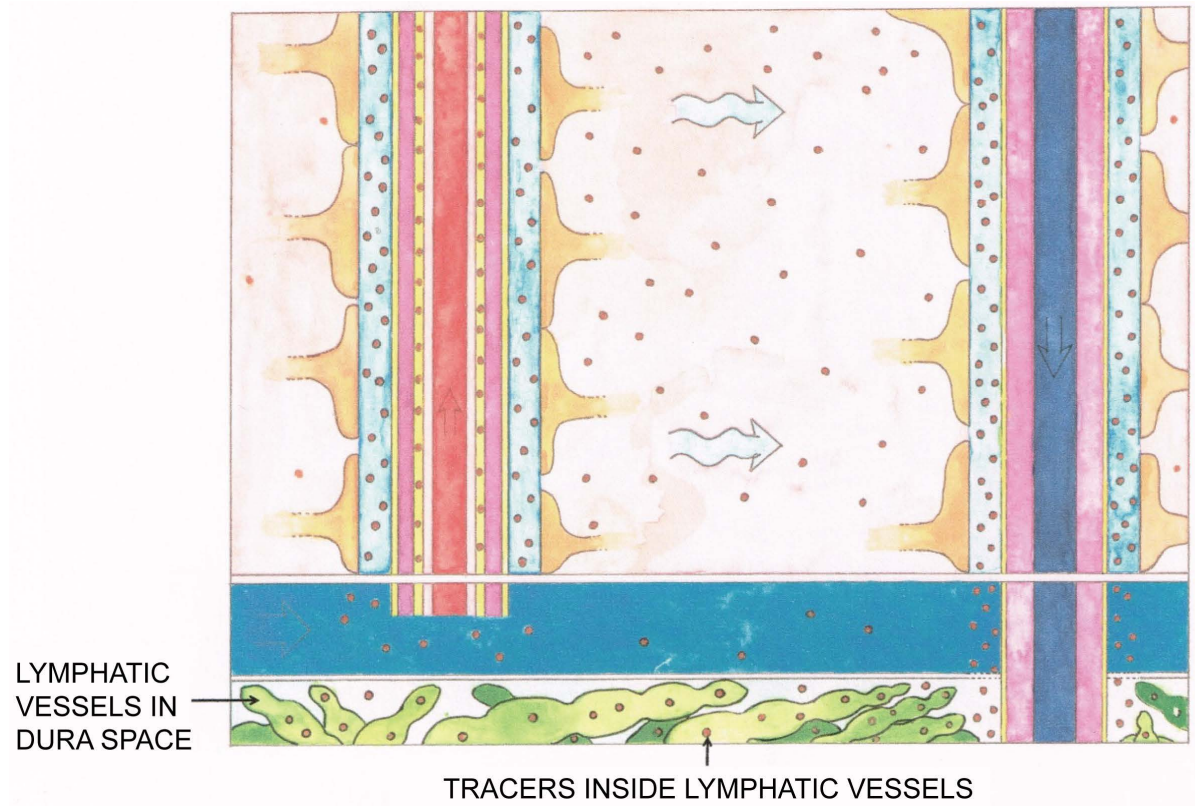

Figure 8. Similar to Figure 4 in Section 5, where we discussed the mixing of the two brain fluids. We simply add the newly discovered glymphatic vessels present (green) in the dura space according to the finding of [130]. The tracers were found inside the glymph vessels. The main trunk/group of glymph vessels pass through certain foramina of the skull bone and join the superficial and/or deep cervical nodes, which are further connected to the lymphatic ducts on both sides of the thymus. In this diagram, the arterial vessel has penetrated into the subarachnoid space from somewhere not shown in the diagram and turn up to pass across a pia layer into the brain, whereas the venous vessel passes through the dura space, and other boundary layers to exit the skull (Figure 8, being painted by author PCWF, is modified from [91] and the presence of the (greenish) lymphatic vessels represents the discovery of [130]). 
vessel walls; (iii) degradation by enzymes such as matrix metalloproteinase-9, glutamate carboxypeptidase II, insulin-degrading enzyme [134]. However, at old age, intra-cranial clearance is not fast enough to clear off this protein. In fact, $\beta$-Amyloid plaques are found in the brain of $\mathrm{AD}$ patients. In addition, there are other pathological brain proteins such as $\alpha$-synuclein and tau protein which are also cleared by a number of enzymes and the processes are not efficient enough during old age. Thus the accumulation of the mentioned proteins is known to be the main causes of a number of chronic brain diseases [135].

One of the key factors in brain clearance is thus how fast the CSF can flow to mix with the ISF so that CSF-BISF can carry the wastes to be drained eventually through the lymph node. In [136], tracers were injected at the cisterna magna and their movement was imaged in real time. With blue-dextran administered via the femoral vein, the vasculature of the live animal could be visualized by imaging. It was demonstrated that during the wake stage, the flow area of the CSF-BISF influx covered was very much smaller than that during the sleep condition [136].

On the other hand, the ISF is generated by the arteries in the brain cortex; these arteries are enclosed by the astrocytic end-feet which are equipped with water channel AQP4. The astrocytic end-feet enclose the arteries and form the BBB. Hence the fluid comes out from the arteries, together with some nutrients and very small molecules to the parenchyma in the brain, is not harmful. However, after receiving metabolic wastes from the neurons and astrocytes, the fluid has to be cleared from the brain.

The amount of CSF-BISF in the parenchyma is therefore dependent on how efficient the Aquaporin 4 channels in transporting water and nutrient to the parenchyma, as well as transporting the "dirty fluid" to the peri-vessel sheaths. Moreover, if there is a change in the total volume of the astrocytes in the brain during the sleep and wake stages, there is a difference in the volume available for CSF-BISF transport. Intuitively, if there is more room for the convective flow of CSF-BISF, we anticipate a faster clearance rate [136]. Moreover, we anticipate that the efficiency of the mixing process across the ependyma is also dependent on the transport efficiency of the AQP4 in the ependymal layer. From the fluid dynamics point of view, if the interstitial space increases, the convective flow of CSF-BISF is more fluent and the incoming CSF and BISF exchange process is more effective. The clearance of the brain wastes is inferred to be associated with the outflow of CSF-BISF to the glymphatic vessels at the subarachnoid space at the base of the skull based on updated research result. The discovery and confirmation of the glymphatic system implies that the brain wastes clearance is more efficient if we learn about under what condition there is more interstitial space. Relatively recently, there is evidence, using in vivo mice models, that natural sleep or anesthesia is associated with a $60 \%$ increase in the interstitial space. The consequence, in turn significantly increases convective exchange of CSF with BISF via the glymphatic system, removing potential neurotoxic waste products such as Beta-amyloid along the peri-vessel pathways. Moreover, sleeping in lateral posture seems to be the best posture so far found for brain clearance [137] [138]. 
Note that AQP4 is expressed in astrocytes and ependymal cells throughout the brain and spinal cord, at the pial and ependymal surfaces in contact with the cerebrospinal fluid (CSF) in the subarachnoid space and the ventricular system. We anticipate that AQP4 plays crucial roles in brain clearance, and there may be difference in the function of this water channel during the wake and sleep states, leading to the observed effect on brain clearance as described above [139].

\subsection{Enhancement of the Glymphatic Clearance System by Non-Invasive Simple Bian Stone Maneuver Techniques}

Bian stone massage techniques came before acupuncture as a set of health-care techniques and therapy in ancient China to treat pains and health disorders [140]. Unfortunately, no literature reporting the ancient maneuver techniques can be found so far. On the other hand, there is extensive literature reporting the efficacy of acupuncture in a range of disorders. However, when there are disorders related to inflammation of connective tissues, and stagnation of lymphatic vessels, massage techniques are frequently used. The present authors have developed a system of non-invasive maneuver techniques using warm Bian stone to treat pains and edema. Some stroke directions and the relevant lymph nodes are indicated in Figure 9. As this paper is devoted to analysis of the five-fluid system, the details of such techniques will not be discussed here. However, to be in line with the present subject matter, it might be fruitful to introduce some simple Bian stone strokes to enhance lymph flow based on experience of formal experience to treat disorders and scientific investigation on physical properties of the Sibin Bian stone material by RKCK [141] [142] [143] and years of experience to treat edema as a health care modality by both authors not under clinical setting. Details

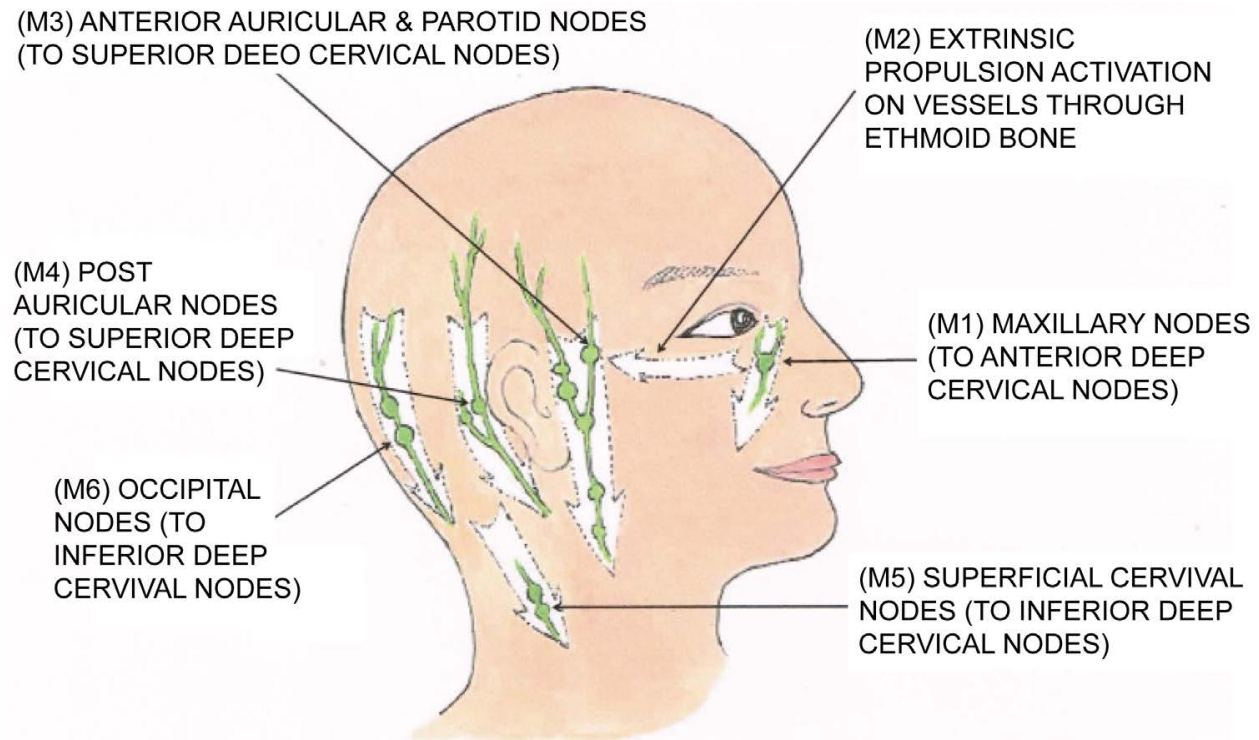

Figure 9. Simple Bian stone massage strokes for consideration to enhance brain drainage. Some crucial lymph nodes are labelled and the arrows indicate the direction of light maneuver strokes. Figure 9 is a painting done by author PCWF. 
of the modality related to specific health disorder, with evidence-based explanation, will be written in other papers.

Incidentally, there are only a few venous vessels which can allow blood flow both ways (see Section 3). If the emissary veins can lead blood into the brain, it could be very harmful. In fact, the regions allowing double-way flow, i.e. the emissary regions have been named the dangerous regions. Mechanical maneuver to avoid venous blood into the brain may be a useful technique in health keeping.

\section{An Overview of the Five-Fluid Circulation System and the Importance of Investigating the Fluid Dynamics of This Integrative System}

Based on the analysis presented in the previous sections, we wish to present an overall schematic representation of the subject matter of this paper. We hypothesize that the Promo Fluid, Blood, (extra-cranial) Interstitial Fluid, the CSF-BISF Fluid, and Lymph (which can be divided into (i) extra-cranial lymph and (ii) glymphatic fluid/ glymph) form a five- fluid circulation system in the human and mammalian bodies. We speculate, without experimental evidence so far, that the water in the PVS comes from either the heart, or ventricles of the brain where there is pumping action to drive fluid flow based on the experimental evidence that PVs have been found to connect the heart and the brain (see Section 2). In Figure 10, the white circle marked "PVS" represents the center station of the PVS, the anatomical location of which is yet to be found. The white tubes indicate that this PVS has connections with other organs based on recent experimental findings. Since it has been revealed that a PV is actually connected to the surface of stomach of the minipig model (see Figure 3(b) of [20]), we propose that the PVS does not exist as an isolated circulation by itself, but rather, joining parts of the other fluid systems analyzed in this paper, forming an integrative whole of the five-fluid system. Such a proposal is also based on the fact that the contents inside the PV fluid are useful in physiological and growth functions.

The cyclic contraction of the heart muscles pumps blood through the arterial vessels. At the capillary beds (represented by the red-blue square-like structure in Figure 10), oxygen molecules (white circles marked O), proteins (orange circles), nutrients (green circles), and cells (marked "cells") of various kinds as described in Section 4, are released to the ISF to nourish the organs. The ISF also receives carbon dioxide (white circles marked C), debris (brown circles) from metabolism and immunity actions; these wastes come from cells of organs. Whereas carbon dioxide molecules together with some "unused proteins" are returned to the blood circulation, the debris plus some cells in the ISF enter the initiative ducts of the lymphatic system, as lymph, the fifth fluid. The green circular structure marked " $\mathrm{N}$ " represents a lymph node, and there are clusters of them at the cervical, axillaries, intestine, neck, inguinals, abdominal and pelvis regions. The purplish circle represents the thymus gland with green circumference representing the left and right lymphatic ducts which branch off to lymph node clusters indicated in the lower part of the diagram. There are green lines joining from the spleen and marrow to the collecting lymphatic duct, implying that these two organs 


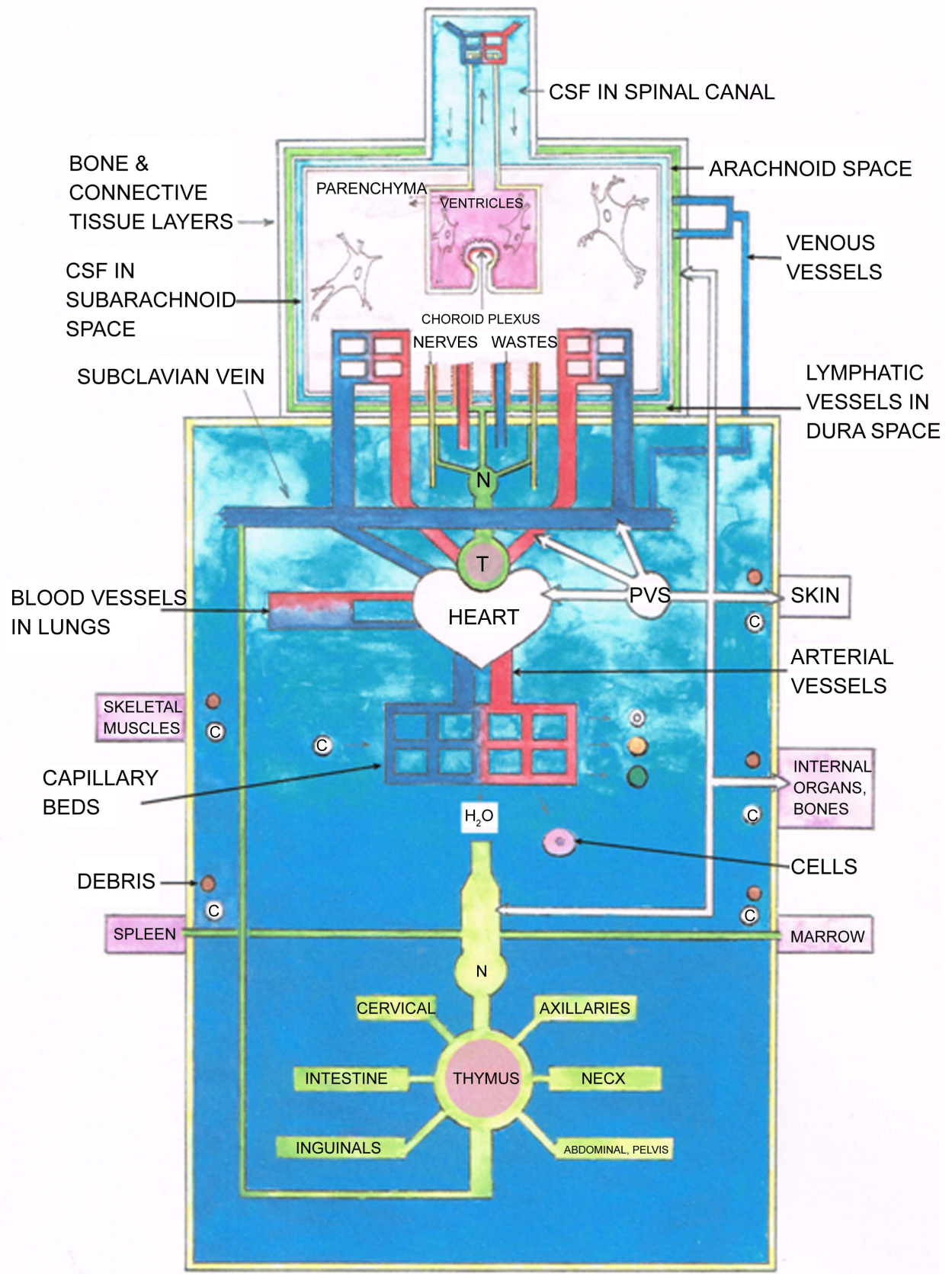

Figure 10. Summary of the five-fluid circulation system. The spinal canal in drawn on the upper part in order that it is not to be mixed up with the head and other parts of the body. The choroid plexus provides the main portion of the CSF in the lateral, third and fourth ventricles in the brain, via the blood-CSF barrier. The saw-tooth barrier represents the epidymocytes via which fluid with small proteins exit from the arterial capillary (in red). The CSF at this stage flows down the spinal canal and is reflected back (with resonance, see Section 5) after receiving fluid from some arterial blood vessels (from the body trunk) and enters the sub-arachnoid space, which surrounds the brain. For many years, the CSF is thought to flow through granulations in the arachnoid space where there are venous vessels, which drain the wastes. In this figure, the arachnoid space and region with venous vessels is represented by a thin light grey boundary, from which two venous vessels emerge on the right side and join the subclavian vein. The brain parenchyma (mainly neurons and astrocytes) in the cortex is painted in pinkish purple color. There 
is fluid flowing from the arterial capillaries into the brain-parenchyma, passes through the bloodbrain barrier, bringing with it nourishment, oxygen and some small proteins. We call this fluid as the brain interstitial fluid (BISF). There is evidence that a small amount of exchange of CSF and BISF takes place across the ependymal thin epithelial layer. However, the majority of the CSF BISF mixing is through a relatively complex process as discussed in Section 5.2. It has been discovered that the wastes can follow the CSF- BISF fluid flowing through the sheaths of the nerves that emerge from the skull bone to the facial region. We therefore draw two yellow small tubes to represent schematically the nerves. Recently, the brain wastes are also found to be carried by the fluid through the sheaths of blood vessels of animal models. The most recent discovery of the existence of lymph vessels in the dura mater inside the skull provides an answer to the long-existing mystery of brain waste clearance. It is highly likely that most of the wastes through the sheaths of nerves, blood vessels already enter the lymph vessels in the dura mater (which may surround most part of the whole brain) and these intra-cranial lymphatic vessels join the extra-cranial lymphatic system outside the skull. The clearance through the veins is better known (Section 3 ) and is not represented here. This is our present model of clearance. The function of the interstitial fluid has been discussed in Section 4. In general, organs leave carbon dioxide and debris in the interstitial fluid after physiological functions, as represented by the white circles (marked c) and brown circles respectively in the diagram. The wastes in the body are drained via the normal way into a number of lymph node clusters such as axillaries, inguinals, neck, etc as marked. These clusters connect the lymphatic ducts on both sides of the thymus which is drawn twice to clarify the anatomical conditions. The spleen and marrow are considered to be organs of the lymphatic system. After carrying out the immunity duties, the lymphatic ducts send the lymph to the venous system at the subclavian vein. We name the lymphatic clearance system inside the skull as the glymphatic system. Based on the detailed discussion in Section 2, we put forth the notion that the Primo Vasculature System supports the functions of various parts of the body - the precursors of proteins are carried by the Primo Vasculature Fluid, and the PVS is represented by the white connections in the diagram. The red tubes and deep blue tubes indicate respectively the arterial and venous vessels, connected by the capillary beds. The five-fluid circulation system is schematically represented as a whole which is a painting done by author PCWF.

are lymphatic organs and supply lymphocytes to the lymph vessels and hence the nodes. A large green tube (below the thymus) connected to an L-shaped green line which joins the large horizontal deep blue vessel represents the fact that after treatment at various node clusters, the lymph fluid joins the blood in the subclavian vein. The rest of the blood circulation is well-known, and will not be repeated here.

Now let us summarize the up-dated findings, according to the detailed discussions in the last section, on the clearance of brain wastes. In the picture, the thymus with a lymph node is duplicated in the upper part of the diagram for convenience of discussion. The uppermost tube in the diagram represents the spinal canal (in up-side-down direction for convenience of discussion too). The choroid plexus generates CSF in the ventricles. The fluid flows down the spinal canal and returns to the subarachnoid space (blue), together with some contribution of fluid from blood vessels in the body below the head (Section 5). CSF and BISF are mixed to become the fourth fluid in our model system. There is certain exchange of these two fluids across the thin boundary (ependymal thin epithelial layer, yellowish) separating the ventricles and the brain cortex, as indicated by two thin, dotted arrows across such a boundary. The two vertical yellow lines represent the nerves from the brain to regions outside the skull bone, such as the 
facial region. Very recently, lymph vessels are found at space close to the ethmoid bone, and even inside the dura space, as represented by the green "boundary" external to the (blue) subarachnoid space. Incidentally, there is mathematical analysis indicating that the wastes can readily follow the sheaths of vessels, rather than diffuse back into the brain, supporting the experimental findings discussed related to the discovery of the glymphatic system [129]. The brain wastes have the chance of entering the glymphatic vessels in the dura space inside the skull via the sheaths of nerves and blood vessels. The wastes follow the nerves can also be drained by the lymph vessels in the facial region close to the ethmoid bone. It has been suggested with evidence that the glymphatic system works much better during sleep, particular in lateral posture. In the last section, we have also introduced simple, non-invasive maneuver techniques that might help enhancement of the glymphatic clearance system.

Even though all of the five fluids discussed in this paper have been known in human and mammalian animals for over half a century, we are only at the infancy stage in understanding the relationship among these fluids as a circulation system. We still have much to understand about the concrete mechanism and conditions under which clearance along sheaths of blood vessels and nerves are efficient, because there is report remarking that clearance occurs along arterial vessels only and also report providing evidence that the wastes are drained via sheaths of veins. There have been a lot of advancement in the knowledge of the PVS in the past ten years, but there are fundamental questions to be answered.

The first question is: where does the PVS come from? Based on the analysis presented in Section 1, we have followed the speculation of [3] that the polar bodies are transformed into the PVS. Experimental verification is certainly essential. However, what matters most, is that the PVS is developed before the cardio vasculature. During pregnancy, the source of water of the PVS is obviously derived from the embryo water. Where does the water of the Primo Vasculature Fluid (PVF) come from after birth? Since there is experimental evidence that the PVs are connected physically with some organs (see Figure 3 of [20]), it is tempting to assume, as other researchers in this field, that the protein precursors and "small stem cell-like cells" are carried by the PVF to enter the attached tissues/organs for the purpose of supporting certain physiological functions, including growth and repair. There are also PVS networks on top of organs such as intestines. Is the PVF playing a similar role like the blood system, and excreting nutrients, pre-cells entities to the ISF? Does PVF bring its constituents directly to organ cells? We now understand that the blood fluid, ISF, CSF-BISF, lymph (with sub-systems of extra-cranial lymph plus glymphatic fluid) form a circulation track, with lymphatic vessels joining the subclavian veins. How does the PVS feed in as part of the circulation system? Needless to say, we certainly wish to know the processes of maturation of the constituents in the PVS. What is the driving force to cause the "automatic" vibration of the PVs?

Above are just some of the many crucial questions. Development of suitable methodologies to measure flow speeds and fluid pressures at different sites of the 
body (animal models and subjects) can provide useful information for analyzing the function of this integrative circulation system.

We propose that the newly discovered glymphatic system (in animals) also exists in the human and mammalian bodies. The mechanisms of fluid flow (with solutes and insoluble molecules) along sheaths of vessels and nerves need to be investigated in details. We begin to learn that sleep, particular in a lateral posture, would enhance the bulk CSF-BISF flow in the brain parenchyma, leading to better efficiency of clearance of the brain wastes from metabolism. Are there other conditions that would expedite the CSF-BISF flow to the dura space where glymphatic vessels are found?

Note also that part of the brain wastes are cleared through veins as discussed in sections $3 \& 7$. Let us consider the vein vessels which pass through the posterior fossa of the cranial vault. There are two main routes: (i) One route (formed by a number of veins) is the vertebral venous plexus following a direction alongside, and within the spinal canal, all the way down to the end part of the spinal cord. (ii) The internal jugular veins form the other route. The upright posture causes a "waterfall" in the brain that follows a steep descent back to the heart. In the upright posture, venous blood flows from the superior sagittal sinus at the top of the brain, passing into the transverse sinus, the sigmoid sinus and eventually joining route (i) or route (ii). It has been pointed out in [47] that the upright position favors cerebral venous outflow into vertebral venous plexus (i.e. route (i)) rather than route (ii)). Therefore it seems that the venous drainage works better in upright posture, but the glymphatic drainage works better in supine position, particular during sleep. Moreover, the emissary veins connect the dura venous blood with the extracranial venous blood and are believed to be involved in dura arteriovenous lesions [47]. Thus maneuvers (such as that introduced briefly in the last section) to avoid back flow of emissary blood into the brain are important protective measures, since the emissary veins are two-way vessels. Practically, we cannot massage the veins in the vertebral plexus, but relaxing the muscles around such vessels would, in our opinion, be a workable modality to enhance the venous drainage of the CSF-BISF fluid. As briefly sketched previously, ISF is involved obviously in edema; ISF dynamics is related to chronic knee inflammation; suitable ISF flow is also necessary for bone growth. There are many aspects to learn about diseases of the connective tissues, with ISF playing roles.

Let us take another concrete example below to demonstrate that understanding the fluid dynamics of the integrative fluid system is involved in the transition from the physio- to pathological state. There are numerous cases of Normal Tension Glaucoma (NTG), meaning that a subject can suffer from open angle glaucoma even if the intraocular pressure is normal [144] [145]. The lamina cribrosa of the eye is subjected to the intraocular pressure and the brain fluid pressure at the retrobulbar space. The eye ball is filled with vitreous humor, a "localized" ISF. We consider that it is the off balance of the stated two fluid pressures that causes the bulging of the optic nerve, leading to the onset of NTG. Moreover, the systolic pressure of the cardio vasculature system affects the rate of generation of CSF, and hence the fluid pressure of the mixed brain fluid at 
the retrobulbar space in general. Inefficient clearance of the brain fluid by the glymphatic system and venous clearance system mentioned in this section might lead to compartmentalization of brain fluid, and it is possible that the fluid pressure at the retrobulbar space is much different from the normal brain fluid pressure. There is diurnal variation of the systolic pressure. Analyzing the flow properties of the four fluids-the blood, (eye) ISF, CSF-BISF, lymph in the dura space, is necessary just to answer one "simple" clinical question: Does a person with low blood pressure have a higher risk of suffering from NTG? No answer to the above question has been published up to present. The above is another example that points to the importance of investigating the fluid dynamics in order to understand the transition from physio- to pathological state.

Based on the analysis presented in this paper, we consider that understanding the fluid dynamics of the integrative five-fluid circulation system is important in analyzing the physio-pathological states of many diseases in medicine. Another potential application is: we cultivate the micro-cells (sanals) in the first fluid (from animal models) and feed them back to one relevant fluid of the other four, as a stem cell therapy investigation.

\section{Acknowledgements}

The authors wish to express their hearty thanks to Mr. Benjamin Fung (brother of Peter Chin Wan Fung) for his unfailing assistance during the preparation of this manuscript. Thanks are also due to Dr. KH Kok, Dr. Junling Gao, University of Hong Kong, for their help also in the preparation of this paper. Figures 2-10 were hand-painted by author Peter Chin Wan Fung. The authors also declare that there is no conflict of interest in this academic project.

\section{References}

[1] Dubinskaya, V.A., Eng, L.S., Rebrow, L.B. and Bykov, V.A. (2007) Comparative Study of the State of Water in Various Human Tissues. Bulletin of Experimental Biology and Medicine, 144, 294-297.

[2] Kim, B.H. (1963) On the Kyungrak System. Journal of Academy of Medical Sciences, 90, $1-41$.

[3] Avijgana, M. and Avijgan, M. (2014) Does the Primo Vascular System Originate from the Polar Body? Integrative Medicine International, 1, 108-118.

[4] Jessen, N.A., Munk, A.S.F. and Nedergaard, I.L.M. (2015) The Glymphatic System: A Beginner's Guide. Neurochemical Research, 40: 2583-2599. http://dx.doi.org/10.1007/s11064-015-1581-6

[5] Kim, B.H. (1965) The Kyungrak System. Journal of Jo Sun Medicine, 108, 1-38.

[6] Podgrabinska, S., Braun, P., Velasco, P., Kloos, B., Pepper, M., Jackson, D.G. and Skobe, M. (2002) Molecular Characterization of Lymphatic Endothelial Cells. Proceedings of the National Academy of Sciences of the United States of America, 99, 16069-16074. http://dx.doi.org/10.1073/pnas.242401399

[7] Hangai-Hoger, N., Cabrales, P., Briceno, J.C., Tsai, A.G. and Intaglietta, M. (2004) Micro- 
lymphatic and Tissue Oxygen Tension in the Rat Mesentery. American Journal of Physiology-Heart and Circulatory Physiology, 286, H868-H883.

[8] Soh, K.S., Kang, K.A. and Ryu, Y.H. (2013) 50 Years of Bong-Han Theory and 10 Years of Primo Vascular System. Evidence-Based Complementary and Alternative Medicine, 2013, Article ID: 587827. http://dx.doi.org/10.1155/2013/587827

[9] Vodyanoy, V., Pustovyy, O., Globa, L. and Sorokulova, I. (2015) Primo-Vascular System as Presented by Bong Han Kim. Evidence-Based Complementary and Alternative Medicine, 2015, Article ID: 361974. http://dx.doi.org/10.1155/2015/361974

[10] Cho, S.J., Kim, B.S. and Park, Y.S. (2004) Threadlike Structures in the Aorta and Coronary Artery of Swine. Journal of International Society of Life Information Science, 22, 609-611.

[11] Johng, H.M., Yoo, J.S., Yoon, T. J., Shin, H.S., Lee, B.C., Lee, C.H. Lee, J.K. and Soh, K.S. (2007) Use of Magnetic Nanoparticles to Visualize Threadlike Structures inside Lymphatic Vessels of Rats. Evidence-Based Complementary and Alternative Medicine, 4, 77-82. http://dx.doi.org/10.1093/ecam/nel057

[12] Yoo, J.S., Kim, M.S., Ogay, V. and Soh, K.S. (2008) In Vivo Visualization of Bonghan Ducts inside Blood Vessels of Mice by Using an Alcian Blue Staining Method. Indian Journal of Experimental Biology, 46, 336-339.

[13] Lee, B.C. and Soh, K.S. (2008) Contrast-Enhancing Optical Method to Observe a Bonghan Duct Floating inside a Lymphatic Vessel of a Rabbit. Lymphology, 41, 178-185.

[14] Lee, B.C., Bae, K.H., Jhon, G.J. and Soh, K.S. (2009) Bonghan System as Mesenchymal Stem Cell Niches and Pathways of Macrophages in Adipose Tissues. Journal of Acupuncture and Meridian Studies, 2, 79-82. http://dx.doi.org/10.1016/S2005-2901(09)60020-0

[15] Lee, B.C., Kim, H.B. and Sung, B. (2011) Network of Endocardial Vessels. Cardiology, 118, 1-7. http://dx.doi.org/10.1159/000323844

[16] Jia, Z.F., Soh, K.S., Zhou, Q., Dong, B. and Yu, W.H. (2011) Study of Novel Threadlike Structures on the Intestinal Fascia of Dog. Journal of Acupuncture and Meridian Studies, 4, 98-101. http://dx.doi.org/10.1016/S2005-2901(11)60014-9

[17] Dai, J. and Soh, K.S. (2011) In Situ Staining of the Primo Vascular System in the Ventricles and Subarachnoid Space of the Brain by Trypan Blue Injection into The lateral Ventricle. Neural Regeneration Research, 6, 2171-2175.

[18] Moon, S.H., Cha, R., Lee, M., Kim, S. and Soh, K.S. (2012) Primo Vascular System in the Subarachnoid Space of the Spinal Cord of a Pig. Journal of Acupuncture and Meridian Studies, 5, 226-233. http://dx.doi.org/10.1016/j.jams.2012.07.006

[19] Lee, S.Y., Lee, B.C., Soh, K.S. and Jhon, G.J. (2012) Development of the Putative Primo Vascular System before the Formation of Vitelline Vessels in Chick Embryos. In: Soh, K.S., Kang, K.A. and Harrison, D.K., Eds., The Primo Vascular System, Springer, New York, 7782. http://dx.doi.org/10.1007/978-1-4614-0601-3_11

[20] Tian, Y.Y., Jing, X.H., Guo, S.G., Jia, S.Y., Zhang, Y.Q., Zhou, W.T., Huang, T. and Zhang, W.B. (2013) Study on the Formation of Novel Threadlike Structure through Intravenous Injection of Heparin in Rats and Refined Observation in Minipigs. Evidence-Based Complementary and Alternative Medicine, 2013, Article ID: 731518. http://dx.doi.org/10.1155/2013/731518

[21] Stefanov, M. and Kim, J.D. (2015) Visualizing the Peripheral Primo Vascular System in Mice Skin by Using the Polymer Mercox. Journal of Pharmacopuncture, 18, 75-79. http://dx.doi.org/10.3831/KPI.2015.18.028

[22] Lee, B.S., Lee, B.C., Park, J.E., Choi, H.K., Choi, S.J. and Soh, K.S. (2014) Primo Vascular System in Human Umbilical Cord and Placenta. Journal of Acupuncture and Meridian 
Studies, 7, 291-297. http://dx.doi.org/10.1016/j.jams.2014.09.002

[23] Lee, B.C., Park, E.S., Nam, T.J., Johng, H.M., Baik, K.Y. and Soh, K.S. (2004) Bonghan Ducts on the Surface of Rat Internal Organs. Journal of International Society of Life Information Science, 22, 455-459.

[24] Yoo, J.S., Hossein Ayati, M., Kim, H.B., Zhang, W.B. and Soh, K.S. (2010) Characterization of the Primo-Vascular System in the Abdominal Cavity of Lung Cancer Mouse Model and Its Differences from the Lymphatic System. PLoS ONE, 5, e9940. http://dx.doi.org/10.1371/journal.pone.0009940

[25] Ogay, V., Bae, K.H., Kim, K.W. and Soh, K.S. (2009) Comparison of the Characteristic Features of Bonghan Ducts, Blood and Lymphatic Capillaries. Journal of Acupuncture and Meridian Studies, 2, 107-117. http://dx.doi.org/10.1016/S2005-2901(09)60042-X

[26] Lee, S.J., Lee, B.C., Nam, C.H., Lee, W.C., Jhang, S.U., Park, H.S. and Soh, K.S. (2008) Proteomic Analysis for Tissues and Liquid from Bonghan Ducts on Rabbit Intestinal Surfaces. Journal of Acupuncture and Meridian Studies, 1, 97-109. http://dx.doi.org/10.1016/S2005-2901(09)60029-7

[27] Kim, J.D., Ogay, V., Lee, B.C., Kim, M.S., Lim, I.B., Woo, H.J., Park, H.J., Kehr, J. and Soh, K.S. (2008) Catecholamine Producing Novel Endocrine Organ: Bonghan System. Medical Acupuncture, 20, 97-102. http://dx.doi.org/10.1089/acu.2008.0600

[28] Pappanon, A.J. and Wier, W.G. (2013) Cardiovascular Physiology. 10th Edition, Elsevier, Philadelphia.

[29] Tortora, G.J. and Derrickson, B. (2012) The Cardiovascular System: Blood Vessels and Hemodynamics. In: Tortora, G.J. and Derrickson, B., Eds., Principles of Anatomy \& Physiology, 13th Edition, John Wiley \& Sons, Hoboken, p.817.

[30] Tortora, G.J. and Derrickson, B. (2012) The Cardiovascular System: Blood Vessels and Hemodynamics. In: Tortora, G.J. and Derrickson, B., Eds., Principles of Anatomy \& Physiology, 13th Edition, John Wiley \& Sons, Hoboken, p. 816.

[31] Boron, W.F. and Boupaep, E.L. (2016) Medical Physiology. 3rd Edition, Elsevier Publisher, Philadelphia.

[32] Késmárky, G., Kenyeres, P., Rábai, M. and Tóth, K. (2008) Plasma Viscosity: A Forgotten Variable. Clinical Hemorheology and Microcirculation, 39, 243-246.

[33] Basu, P., Sen, U., Tyagi, N., and Tyagi, S.C. (2010) Blood Flow Interplays with Elastin: Collagen and MMP: TIMP Ratios to Maintain Healthy Vascular Structure and Function. Vascular Health and Risk Management, 6, 215-228.

[34] Rucklidge, G.J., Milne, G., McGaw, B.A., Milne, E. and Robins, S.P. (1992) Turnover Rates of Different Collagen Types Measured by Isotope Ratio Mass Spectrometery. Biochimica et Biophysica Acta (BBA)—General Subjects, 1156, 57-61.

[35] Libby, P. and Lee, R.T. (2000) Matrix Matters. Circulation, 102, 1874-1876. http://dx.doi.org/10.1161/01.CIR.102.16.1874

[36] Ota, R., Kutihara, C. and Tsou, T.L. (2009) Roles of Matrix Metalloproteinases in FlowInduced outward Vascular Remodeling. Journal of Cerebral Blood Flow \& Metabolism, 29, 1547-1558. http://dx.doi.org/10.1038/jcbfm.2009.77

[37] Discher, D.E., Janmey, P.A. and Wang, Y.L. (2005) Tissue Cells Feel and Respond to the Stiffness of Their Substrate. Science, 310, 1139-1143. http://dx.doi.org/10.1126/science.1116995

[38] Pelham, R.J. and Wang, Y.L. (1997) Cell Locomotion and Focal Adhesions Are Regulated by Substrate Flexibility. Proceedings of the National Academy of Sciences of the United 
States of America, 94, 13661-13665. http://dx.doi.org/10.1073/pnas.94.25.13661

[39] Takagi, Y., Homsher, E.E., Goldman, Y.E. and Shuman, H. (2006) Force Generation in single Conventional Actomyosin Complexes under High Dynamic Load. Biophysical Journal, 90, 1295-1307. http://dx.doi.org/10.1529/biophysj.105.068429

[40] Reilly, K. (2015) Cardiac Fibrosis: New Treatments in Cardiovascular Medicine. U.S. Pharmacist, 40, 32-35.

[41] Shapira-Schweitzer, K. and Seliktar, D. (2007) Matrix Stiffness Affects Spontaneous Contraction of Cardiomyocytes Cultured within a PEGylated Fibrinogen Biomaterial. Acta Biomaterialia, 3, 33-41. http://dx.doi.org/10.1016/j.actbio.2006.09.003

[42] Engler, A.J., Carag-Krieger, C., Johnson, C.P., Raab, M., Tang, H.Y., Speicher, D.W., Sanger, J.W., Sanger, J.M. and Dische, D.E. (2008) Embryonic Cardiomyocytes Beat Best on a Matrix with Heart-Like Elasticity: Scar-Like Rigidity Inhibits Beating. Journal of Cell Science, 121, 3794-3802. http://dx.doi.org/10.1242/jcs.029678

[43] Fung, P.C.W. (2013) Chapter 5: Plausible Biomedical Consequences of Acupuncture Applied at Sites Characteristic of Acupoints in the Connective-Tissue-Interstitial-Fluid System. In: Chen, L.L. and Cheng, T.O., Eds., Acupuncture in Modern Medicine, IntechOpen, Rijeka, 95-131.

[44] Mortazavi, M.M., Tubbs, R.S., Riech, S., Verma, K., Shoja, M.M., Zurada, A., Benninger, B., Loukas, M. and Cohen-Gadol, A.A. (2012) Anatomy and Pathology of the Cranial Emissary Veins: A Review with Surgical Implications. Neurosurgery, 70, 1312-1318. http://dx.doi.org/10.1227/NEU.0b013e31824388f8

[45] Reis, C.V.C., Deshmukh, V., Zabramski, J.M., Crusius, M., Desmukh, P., Spetzler, R.F. and Preul, M.C. (2007) Anatomy of the Mastoid Emissary Vein and Venous System of the Posterior Neck Region: Neurosurgical Implications. Neurosurgery, 61, 193-201. http://dx.doi.org/10.1227/01.neu.0000303217.53607.d9

[46] Freire, A.R., Rossi, A.C., de Oliveira, V.C.S., Prado, F.B., Caria, P.H.F. and Botacin, P.R. (2013) Emissary Foramens of the Human Skull: Anatomical Characteristics and Its Relations with Clinical Neurosurgery. International Journal of Morphology, 31, 287-292. http://dx.doi.org/10.4067/S0717-95022013000100045

[47] San Millán Ruíz, D., Gailloud, P., Rüfenacht, D.A., Delavelle, J., Henry, F. and Fasel, J.H.D. (2002) The Craniocervical Venous System in Relation to Cerebral Venous Drainage. AJNR American Journal of Neuroradiology, 23, 1500-1508.

[48] Wysocki, J., Reymond, J., Skarżyński, H. and Wróbel, B. (2006) The Size of Selected Human Skull Foramina in Relation to Skull Capacity. Folia Morphologica, 65, 301-308.

[49] Murlimanju, B.V., Chettiar, G.K., Prameela, M.D., Mamatha Tonse, M., Kumar, N., Saralaya, V.V. and Prabhu, L.V. (2014) Mastoid Emissary Foramina: An Anatomical Morphological Study with Discussion on Their Evolutionary and Clinical Implications. Anatomy \& Cell Biology, 47, 202-206. http://dx.doi.org/10.5115/acb.2014.47.3.202

[50] Kielty, C.M., and Grant, M.E. (2002) The Collagen Family: Structure, Assembly, and Organization in the Extracellular Matrix. In: Royce, P.M. and Steinmann, B., Eds., Connective Tissue and Its Heritable Disorders, Wiley-Liss, Inc., New York, 159-221. http://dx.doi.org/10.1002/0471221929.ch2

[51] Meisenberg, G., and Simmons, W.H. (2006) Principles of Medical Biochemistry. Elsevier Health Sciences, Philadelphia, p. 243.

[52] Swartz, M.A. and Fleury, M.E. (2007) Interstitial Flow and Its Effects in Soft Tissues. Annual Review of Biomedical Engineering, 9, 229-256.

http://dx.doi.org/10.1146/annurev.bioeng.9.060906.151850 
[53] Helm, C.L.E., Fleury, M.E., Zisch, A.H., Boschetti, F. and Swartz, M.A. (2005) Synergy between Interstitial Flow and VEGF Directs Capillary Morphogenesis in Vitro through a Gradient Amplification Mechanism. Proceedings of the National Academy of Sciences of the United States of America, 102, 15779-15784. http://dx.doi.org/10.1073/pnas.0503681102

[54] Helm, C.L.E., Zisch, A.H. and Swartz, M.A. (2006) Engineered Blood and Lymphatic Capillaries in 3D VEGF-Fibrin-Collagen Matrices with Interstitial Flow. Biotechnology and Bioengineering, 96, 167-176. http://dx.doi.org/10.1002/bit.21185

[55] Ng, C.P., Helm, C.L.E. and Swartz, M.A. (2004) Interstitial Flow Differentially Stimulates Blood and Lymphatic Endothelial Cell Morphogenesis in Vitro. Microvascular Research, 68, 258-264. http://dx.doi.org/10.1016/j.mvr.2004.08.002

[56] Semino, C.E., Kamm, R.D. and Lauffenburger, D.A. (2006) Autocrine EGF Receptor Activation Mediates Endothelial Cell Migration and Vascular Morphogenesis Induced by VEGF under Interstitial Flow. Experimental Cell Research, 312, 289-298.

[57] Rutkowski, J.M., Boardman, K.C. and Swartz, M.A. (2006) Characterization of Lymphangiogenesis in a Model of Adult Skin Regeneration. American Journal of Physiology-Heart and Circulatory Physiology, 291, H1402-H1410. http://dx.doi.org/10.1152/ajpheart.00038.2006

[58] Buschmann, M.D., Gluzband, Y.A., Grodzinsky, A.J. and Hunziker, E.B. (1995) Mechanical Compression Modulates Matrix Biosynthesis in Chondrocyte Agarose Culture. Journal of Cell Science, 108, 1497-1508.

[59] Mow, V.C., Holmes, M.H. and Lai, W.M. (1984) Fluid Transport and Mechanicalproperties of Articular-Cartilage-A Review. Journal of Biomechanics, 17, 377-394. http://dx.doi.org/10.1016/0021-9290(84)90031-9

[60] Grodzinsky, A.J., Levenston, M.E., Jin, M. and Frank, E.H. (2000) Cartilage Tissue Remodeling in Response to Mechanical Forces. Annual Review of Biomedical Engineering, 2, 691 713. http://dx.doi.org/10.1146/annurev.bioeng.2.1.691

[61] Ikegame, M., Ishibashi, O., Yoshizawa, T., Shimomura, J., Komori, T., Ozawa, H. and Kawashima, H. (2001) Tensile Stress Induces Bone Morphogenetic Protein 4 in Preosteoblastic and Fibroblastic Cells, Which Later Differentiate into Osteoblasts Leading to Osteogenesis in the Mouse Calvariae in Organ Culture. Journal of Bone and Mineral Research, 16, 24-32.http://dx.doi.org/10.1359/jbmr.2001.16.1.24

[62] Ng, C.P. and Swartz, M.A. (2006) Mechanisms of Interstitial Flow-Induced Remodeling of Fibroblast-Collagen Cultures. Annals of Biomedical Engineering, 34, 446-454. http://dx.doi.org/10.1007/s10439-005-9067-3

[63] Wang, S. and Tarbell, JM. (2000) Effect of Fluid Flow on Smooth Muscle Cells in a 3-Dimensional Collagen Gel Model. Arteriosclerosis, Thrombosis, and Vascular Biology, 20, 2220-2225. http://dx.doi.org/10.1161/01.ATV.20.10.2220

[64] Ethier, C.R., Johnson, M. and Ruberti, J. (2004) Ocular Biomechanics and Biotransport. Annual Review of Biomedical Engineering, 6, 249-273. http://dx.doi.org/10.1146/annurev.bioeng.6.040803.140055

[65] Nonaka, S., Tanaka, Y., Okada, Y., Takeda, S. and Harada, A. (1998) Randomization of Left-Right Asymmetry due to Loss of Nodal Cilia Generating Leftward Flow of Extraembryonic Fluid in Mice Lacking KIF3B Motor Protein. Cell, 95, 829-837. http://dx.doi.org/10.1016/S0092-8674(00)81705-5

[66] Guyton, A.C. (1991) Textbook of Medical Physiology. Saunders, Philadelphia.

[67] Guyton, A.C., Scheel, K. and Murphree, D. (1966) Interstitial Fluid Pressure. 3. Its Effect on Resistance to Tissue Fluid Mobility. Circulation Research, 19, 412-419. 
http://dx.doi.org/10.1161/01.RES.19.2.412

[68] Guyton, A.C., Prather, J., Scheel, K. and McGehee, J. (1966) Interstitial Fluid Pressure. 4. Its Effect on Fluid Movement through Capillary Wall. Circulation Research, 19, 1022-1030. http://dx.doi.org/10.1161/01.RES.19.6.1022

[69] Renkin, E.M. (1986) Some Consequences of Capillary-Permeability to MacromoleculesStarlings Hypothesis Reconsidered. American Journal of Physiology-Heart and Circulatory Physiology, 250, H706-H710.

[70] Schmid-Schonbein, G.W. (1990) Microlymphatics and Lymph-Flow. Physiological Reviews, 70, 987-1028.

[71] Swartz, M.A. (2001) The Physiology of the Lymphatic System. Advanced Drug Delivery Reviews, 50, 3-20. http://dx.doi.org/10.1016/S0169-409X(01)00150-8

[72] Awwad, H.K., Elnaggar, M., Mocktar, N. and Barsoum, M. (1986) Intercapillary Distance Measurement as an Indicator of Hypoxia in Carcinoma of the Cervix Uteri. International Journal of Radiation Oncology, Biology, Physics, 12, 1329-1333. http://dx.doi.org/10.1016/0360-3016(86)90165-3

[73] Less, J.R., Skalak, T.C., Sevick, E.M. and Jain, R.K. (1991) Microvascular Architecture in a Mammary-Carcinoma-Branching Patterns and Vessel Dimensions. Cancer Research, 51, 265-273.

[74] Ng, C.P. and Swartz, M.A. (2003) Fibroblast Alignment under Interstitial Fluid Flow Using a Novel 3-D Tissue Culture Model. American Journal of Physiology-Heart and Circulatory Physiology, 284, H1771-H1777. http://dx.doi.org/10.1152/ajpheart.01008.2002

[75] Aukland, K. and Reed, R.K. (1993) Interstitial-Lymphatic Mechanisms in the Control of Extracellular Fluid Volume. Physiological Reviews, 73, 1-78.

[76] Kwan, M.K., Lai, W.M. and Mow, V.C. (1984) Fundamentals of Fluid Transport through Cartilage in Compression. Annals of Biomedical Engineering, 12, 537-558. http://dx.doi.org/10.1007/BF02371448

[77] Reed, R.K., Rubin, K., Wiig, H. and Rodt, S.A. (1992) Blockade of Beta 1-Integrins in Skin Causes Edema through Lowering of Interstitial Fluid Pressure. Circulation Research, 71, 978-983. http://dx.doi.org/10.1161/01.RES.71.4.978

[78] Wiig, H., Rubin, K. and Reed, R.K. (2003) New and Active Role of the Interstitium in Control of Interstitial Fluid Pressure: Potential Therapeutic Consequences. Acta Anaesthesiologica Scandinavica, 47, 111-121. http://dx.doi.org/10.1034/j.1399-6576.2003.00050.x

[79] Carmeliet, P. and Jain, R.K. (2000) Angiogenesis in Cancer and Other Diseases. Nature, 407, 249-257. http://dx.doi.org/10.1038/35025220

[80] Bunn, H.F. and Poyton, R.O. (1996) Oxygen Sensing and Molecular Adaptation to Hypoxia. Physiological Reviews, 76, 839-885.

[81] Boardman, K.C., and Swartz, M.A. (2003) Interstitial Flow as a Guide for Lymphangiogenesis. Circulation Research, 92, 801-808.

[82] Swartz, M.A., Kaipainen, A., Netti, P.A., Brekken, C., Boucher, Y., Grodzinsky, A.J. and Jain, R.K. (1999) Mechanics of Interstitial-Lymphatic Fluid Transport: Theoretical Foundation and Experimental Validation. Journal of Biomechanics, 32, 1297-1307. http://dx.doi.org/10.1016/s0021-9290(99)00125-6

[83] http://www.uptodate.com/contents/cerebrospinal-fluid-physiology-and-utility-

[84] Reymond, P., Merenda, F., Perren, F., Rufenacht, D. and Stergiopulos, N. (2009) Validation of a One-Dimensional Model of the Systemic Arterial Tree. American Journal of Physiology-Heart and Circulatory Physiology, 297, H208-H222. 
[85] Martin, B.A., Reymond, P., Novy, J., Balédent, O. and Stergiopulos, N. (2012) A Coupled Hydrodynamic Model of the Cardiovascular and Cerebrospinal Fluid System. American Journal of Physiology_Heart and Circulatory Physiology, 302, H1492-H1509. http://dx.doi.org/10.1152/ajpheart.00658.2011

[86] Redzic, Z.B., Preston, J.E., Duncan, J.A., Chodobski, A. and Szmydynger-Chodobska, J. (2005) The Choroid Plexus-Cerebrospinal Fluid System: From Development to Aging. Current Topics in Developmental Biology, 71, 1-52. http://dx.doi.org/10.1016/S0070-2153(05)71001-2

[87] Iliff, J.J. and Nedergaard, M. (2013) Is There a Cerebral Lymphatic System? Stroke, 44, S93-S95. http://dx.doi.org/10.1161/STROKEAHA.112.678698

[88] Abbott, N.J. (2004) Evidence for Bulk Flow of Brain Interstitial Fluid: Significance for Physiology and Pathology. Neurochemistry International, 45, 545-552. http://dx.doi.org/10.1016/j.neuint.2003.11.006

[89] Brown, P.D., Davies, S.L., Speake, T. and Millar, I.D. (2004) Molecular Mechanisms of Cerebrospinal Fluid Production. Neuroscience, 129, 955-968.

http://dx.doi.org/10.1016/j.neuroscience.2004.07.003

[90] Praetorius, J. (2007) Water and Solute Secretion by the Choroid Plexus. Pflügers ArchivEuropean Journal of Physiology, 454, 1-18. http://dx.doi.org/10.1007/s00424-006-0170-6

[91] Iliff, J.J., Wang, M.H., Liao, Y.H., Plogg, B.A., Peng, W.G., Gundersen, G.A., Benveniste, H., Vates, G.E., Deane, R., Goldman, S.A., Nagelhus, E.A. and Nedergaard, M. (2012) A Paravascular Pathway Facilitates CSF Flow through the Brain Parenchyma and the Clearance of Interstitial Solutes, Including Amyloid $\beta$. Science Translational Medicine, 4, 147ra111. http://dx.doi.org/10.1126/scitranslmed.3003748

[92] Iliff, J.J., Lee, H.D., Yu, M., Feng, T., Logan, J., Nedergaard, M. and Benveniste, H. (2013) Brain-Wide Pathway for Waste Clearance Captured by Contrast-Enhanced MRI. Journal of Clinical Investigation, 123, 1299-1309. http://dx.doi.org/10.1172/JCI67677

[93] Šimić, G., Leko, M.B., Wray, S., Harrington, C., Delalle, I., Jovanov-Milošević, N., Bažadona, D., Buée, L., de Silva, R., Di Giovanni, G., Wischik, C. and Hof, P.R. (2016) Tau Protein Hyperphosphorylation and Aggregation in Alzheimer's Disease and Other Tauopathies, and Possible Neuroprotective Strategies. Biomolecules, 6, 6.

[94] Wigle, J.T. and Oliver, G. (1999) Prox1 Function Is Required for the Development of the Murine Lymphatic System. Cell, 98, 769-778.

http://dx.doi.org/10.1016/S0092-8674(00)81511-1

[95] Wilting, J., Papoutsi, M., Othman-Hassan, K., Rodriguez-Nieden-fuhr, M., Prols, F., Tomarev, S. I. and Eichmann, A. (2001) Development of the Avian Lymphatic System. Microscopy Research and Technique, 55, 81-91. http://dx.doi.org/10.1002/jemt.1159

[96] von der Weid, P.Y. and Zawieja, D.C. (2004) Lymphatic Smooth Muscle: The Motor Unit of Lymph Drainage. The International Journal of Biochemistry \& Cell Biology, 36, 1147 1153. http://dx.doi.org/10.1016/j.biocel.2003.12.008

[97] Ohtani, Y. and Ohtani, O. (2001) Postnatal Development of Lymphatic Vessels and Their Smooth Muscle Cells in the Rat Diaphragm: A Confocal Microscopic Study. Archives of Histology and Cytology, 64, 513-522. http://dx.doi.org/10.1679/aohc.64.513

[98] von der Weid, P.Y., Lee, S., Imtiaz Mohammad, S., Zawieja, D.C. and Davies, M.J. (2014) Electrophysiological Properties of Rat Mesenteric Lymphatic Vessels and Their Regulation by Stretch. Lymphatic Research and Biology, 12, 66-75. http://dx.doi.org/10.1089//rb.2013.0045

[99] Goldsby, R., Kindt, T.J., Osborne, B.A. and Kuby, J. (2003) Chapter 2: Cells and Organs of 
the Immune System. In: Immunology, 5th Edition, W. H. Freeman and Company, New York, 24-56.

[100] Swirski, F.K., Nahrendorf, M., Etzrodt, M., Wildgruber, M., Cortez-Retamozo, V., Panizzi, P., Figueiredo, J.L., Kohler, R.H., Chudnovskiy, A., Waterman, P., Aikawa, E., Mempel, T.R., Libby, P., Weissleder, R. and Pittet, M.J. (2009) Identification of Splenic Reservoir Monocytes and Their Deployment to Inflammatory Sites. Science, 325, 612-616. http://dx.doi.org/10.1126/science.1175202

[101] Szuba, A., Shin, W.S., Strauss, H.W. and Rockson, S. (2003) The Third Circulation: Radionuclide Lymphoscintigraphy in the Evaluation of Lymphedema. Journal of Nuclear Medicine, 44, 43-57.

[102] Norrmén, C., Tammela, T., Petrova, T.V. and Alitalo, K. (2011) Basic Science for Clinicians, Biological Basis of Therapeutic Lymphangiogenesis. Circulation, 123, 1335-1351. http://dx.doi.org/10.1161/CIRCULATIONAHA.107.704098

[103] Choi, I., Lee, S. and Hong, Y.K. (2012) The New Era of the Lymphatic System: No Longer Secondary to the Blood Vascular System. Cold Spring Harbor Perspectives in Medicine, 2, a006445. http://dx.doi.org/10.1101/cshperspect.a006445

[104] Hall, J.G., Morris, B. and Woolley, G. (1965) Intrinsic Rhythmic Propulsion of Lymph in the Unanaesthetized Sheep. The Journal of Physiology, 180, 336-349.

[105] Benoit, J.N., Zawieja, D.C., Goodman, A.H. and Granger, H.J. (1989) Characterization of Intact Mesenteric Lymphatic Pump and Its Responsiveness to Acute Edemagenic Stress. American Journal of Physiology, 257, H2059-H2069.

[106] Gashev, A.A. (1991) The Mechanism of the Formation of a Reverse Fluid Filling in the Lymphangions. Fiziologicheskii Zhurnal SSSR Imeni I. M. Sechenova, 77, 63-69 (in Russian).

[107] Gashev, A.A., Davis, M.J. and Zawieja, D.C. (2002) Inhibition of the Active Lymph Pump by Flow in Rat Mesenteric Lymphatics and Thoracic Duct. Journal of Physiology, 540, 1023-1037. http://dx.doi.org/10.1113/jphysiol.2001.016642

[108] Olszewski, W.L. and Engeset, A. (1980) Intrinsic Contractility of Prenodal Lymph Vessels and Lymph Flow in Human Leg. American Journal of Physiology, 239, H775-H783.

[109] Webb Jr., R.C.W. and Starzl, T.E. (1953) The Effect of Blood Vessel Pulsations on Lymph Pressure in Large Lymphatics. Bulletin of the Johns Hopkins Hospital, 93, 401-407.

[110] Van Helden, D.F., Von der Weid, P.Y. and Crowe, M.J. (1995) Electrophysiology of Lymphatic Smooth Muscle. In: Bert, J., Laine, G.A., McHale, N.G., Reed, R. and Winlove, P., Eds., Connective Tissue, and Lymphatics, Portland Press, London, 221-236.

[111] Szuba, A. and Rockson, S.G. (1998) Lymphedema: Classification. Vascular Medicine, 3, 145-156. http://dx.doi.org/10.1177/1358836X9800300209

[112] Parviainen, E.H.T., Vuorela, J., Toivanen, J., Nikula, T. and Vihko, V. (1997) Lymph Flow Dynamics in Exercising Human Skeletal Muscle as Detected by Scintography. Journal of Physiology, 504, 233-239. http://dx.doi.org/10.1111/j.1469-7793.1997.233bf.x

[113] Reed, R.K. (1985) Transcapillary Extravasation Rate of Albumin in Rat Skeletal Muscle. Effect of Motor Activity. Acta Physiologica Scandinavica, 125, 719-725. http://dx.doi.org/10.1111/j.1748-1716.1985.tb07775.x

[114] Motimer, P.S., Simmonds, R., Rezvani, M., Robbins, M., Hopewell, J.W. and Ryan, T.J. (1990) The Measurement of Skin Lymph Flow by Isotope Clearance-Reliability, Reproducibility, Injection Dynamics and the Effects of Massage. Journal of Investigative Dermatology, 95, 677-682. http://dx.doi.org/10.1111/1523-1747.ep12514347 
[115] Jackson, R.T., Tigges, J. and Arnold, W. (1979) Subarachnoid Space of the CNS, Nasal Mucosa, and Lymphatic System. Archives of Otolaryngology, 105, 180-184. http://dx.doi.org/10.1001/archotol.1979.00790160014003

[116] Koh, L., Zakharov, A. and Johnston, M. (2005) Integration of the Subarachnoid Space and Lymphatics: Is It Time to Embrace a New Concept of Cerebrospinal Fluid Absorption? $\mathrm{Ce}$ rebrospinal Fluid Research, 2, 6.

[117] Löwhagen, P., Johansson, B.B. and Nordbor, C. (1994) The Nasal Route of Cerebrospinal Fluid Drainage in Man. A Light-Microscope Study. Neuropathology \& Applied Neurobiology, 20, 543-550. http://dx.doi.org/10.1111/j.1365-2990.1994.tb01008.x

[118] Zhang, E.T., Richards, H.K., Kida, S. and Weller, R.O. (1992) Directional and Compartmentalised Drainage of Interstitial Fluid and Cerebrospinal Fluid from the Rat Brain. Acta Neuropathologica, 83, 233-239. http://dx.doi.org/10.1007/BF00296784

[119] Johnston, M., Zakharov, A., Papaiconomou, C., Salmasi, G. and Armstrong, D. (2004) Evidence of Connections between Cerebrospinal Fluid and Nasal Lymphatic Vessels in $\mathrm{Hu}-$ mans, Non-Human Primates and Other Mammalian Species. Cerebrospinal Fluid Research, 1, 2. http://dx.doi.org/10.1186/1743-8454-1-2

[120] Zakharov, A., Papaiconomou, C., Djenic, J., Midha, R. and Johnston, M. (2003) Lymphatic Cerebrospinal Fluid Absorption Pathways in Neonatal Sheep Revealed by Subarachnoid Injection of Microfil. Neuropathology and Applied Neurobiology, 29, 563-573. http://dx.doi.org/10.1046/j.0305-1846.2003.00508.x

[121] Zakharov, A., Papaiconomou, C. and Johnston, M. (2004) Lymphatic Vessels Gain Access to Cerebrospinal Fluid through Unique Association with Olfactory Nerves. Lymphatic Research and Biology, 2,139-146. http://dx.doi.org/10.1089/lrb.2004.2.139

[122] Cursiefen, C., Schlotzer-Schrehard, U., Küchle, M., Sorokin, L., Breiteneder-Geleff, S., Alitalo, K. and Jackson, D. (2002) Lymphatic Vessels in Vascularized Human Corneas: Immunohistochemical Investigation Using LYVE-1 and Podoplanin. Investigative Ophthalmology \& Visual Science, 43, 2127-2135.

[123] Andres, K.H., von During, M., Muszynski, K. and Schmidt, R.F. (1987) Nerve Fibres and Their Terminals of the Dura Mater Encephali of the Rat. Anatomy and Embryology, 175, 289-301. http://dx.doi.org/10.1007/BF00309843

[124] Brierley, J.B. and Field, E.J. (1948) The Connexions of the Spinal Sub-Arachnoid Space with the Lymphatic System. Journal of Anatomy, 82,153-166.

[125] Kida, S., Pantazis, A. and Weller, R.O. (1993) CSF Drains Directly from the Subarachnoid Space into Nasal Lymphatics in the Rat, Anatomy, Histology and Immunological Significance. Neuropathology and Applied Neurobiology, 19, 480-488. http://dx.doi.org/10.1111/j.1365-2990.1993.tb00476.x

[126] Miura, M., Kato, S. and von Ludinghausen, M. (1998) Lymphatic Drainage of the Cerebrospinal Fluid from monkey Spinal Meninges with Special Reference to the Distribution of the Epidural Lymphatics. Archives of Histology and Cytology, 61, 277-286.

http://dx.doi.org/10.1679/aohc.61.277

[127] Bozanovic-Sosic, R., Mollanji, R. and Johnston, M.G. (2001) Spinal and Cranial Contributions to Total Cerebrospinal Fluid Transport. American Journal of Physiology-Regulatory Integrative and Comparative Physiology, 281, R909-R916.

[128] Carare, R., Bernardes-Silva, M., Newman, T., Page, A., Nicoll, J., Perry, V. and Weller, R. (2008) Solutes, but Not Cells, Drain from the Brain Parenchyma along Basement Membranes of Capillaries and Arteries: Significance for Cerebral Amyloid Angiopathy and Neuroimmunology. Neuropathology and Applied Neurobiology, 34, 131-144. 
http://dx.doi.org/10.1111/j.1365-2990.2007.00926.x

[129] Diem, A.K., Tan, M., Bressloff, N.W., Hawkes, C., Morris, A.W.J., Weller, R.O. and Carare, R.O. (2016) A Simulation Model of Periarterial Clearance of Amyloid- $\beta$ from the Brain. Frontier in Aging Neuroscience, 18, 1-11.

[130] Aspelund, A., Antila, S., Proulx, S.T., Karlsen, T.V., Karaman, S., Detmar, M., Wiig, H. and Alitalo, K. (2015) A Dural Lymphatic Vascular System that Drains Brain Interstitial Fluid and Macromolecules. The Journal of Experimental Medicine, 212, 991-999. http://dx.doi.org/10.1084/jem.20142290

[131] Louveau, A., Smirnov, I., Keyes, T.J., Eccles, J.D., Sherin, J., Rouhani, J., Peske, D., Derecki, N.C., Castle, D., Mandell, J.W., Lee, K.S., Harris, T.H. and Kipnis, J. (2016) Structural and Functional Features of Central Nervous System Lymphatic Vessels. Nature, 523, 337-341. http://dx.doi.org/10.1038/nature14432

[132] Bulat, M. and Marijan Klarica, M. (2011) Recent Insights into a New Hydrodynamics of the Cerebrospinal Fluid. Brain Research Reviews, 659, 99-112. http://dx.doi.org/10.1016/j.brainresrev.2010.08.002

[133] Tanzi, R.E. (2012) The Genetics of Alzheimer Disease. Cold Spring Harbor Perspectives in Medicine, 2, a006296. http://dx.doi.org/10.1101/cshperspect.a006296

[134] Yoon, S.S. and Jo, S.A. (2012) Mechanisms of Amyloid-Beta Peptide Clearance: Potential Therapeutic Targets for Alzheimer's Disease. Biomolecules and Therapeutics, 20, 245-255. http://dx.doi.org/10.4062/biomolther.2012.20.3.245

[135] Chesser, A.S., Pritchard, S.M. and Johnson, G.V.W. (2013) Tau Clearance Mechanisms and Their Possible Role in the Pathogenesis of Alzheimer Disease. Frontiers in Neurology, 4, 122. http://dx.doi.org/10.3389/fneur.2013.00122

[136] Xie, L., Kang, H., Xu, Q., Chen, M.J., Liao, Y., Thiyagarajan, M., O’Donnell, J., Christensen, D.J., Nicholson, C., Iliff, J.J., Takano, T., Deane, R. and Nedergaard, M. (2013) Sleep Drives Metabolite Clearance from the Adult Brain. Science, 342, 373-377. http://dx.doi.org/10.1126/science.1241224

[137] Clark, C.N. and Warren, J.D. (2013) A Hypnic Hypothesis of Alzheimer's Disease. Neurodegenerative Diseases, 12,165-176. http://dx.doi.org/10.1159/000350060

[138] Mendelsohn, A.R. and Larrick, J.W. (2013) Sleep Facilitates Clearance of Metabolites from the Brain: Glymphatic Function in Aging and Neurodegenerative Diseases. Rejuvenation Research, 16, 518-523. http://dx.doi.org/10.1089/rej.2013.1530

[139] Verkman, A.S., Devin, K., Binder, D.K., Bloch, O., Auguste, K. and Papadopoulos, M.C. (2006) Three Distinct Roles of Aquaporin-4 in Brain Function Revealed by Knockout Mice. Biochimica et Biophysica Acta (BBA) -Biomembranes, 1758, 1085-1093. http://dx.doi.org/10.1016/j.bbamem.2006.02.018

[140] Pivot, M. (1980) Huangdi's Internal Classic (Revised Translation). People's Health Publishing House, Beijing, 155-173.

[141] Xie, X.D., Wang, F.Y., Sun, Z.Y., Lo, P.L., Kong, K.C. and Xie, N.Z. (2011) Petrological and Mineralogical Studies of the Sibin Bian-Stone, a Material for Making Acupuncture Tools in Ancient China. Proceedings of the 10 th International Congress for Applied Mineralogy (ICAM), Trondheim, 1-5 August 2011, 773-780.

[142] Lo, P.L., Kong, K.C., Huang, Y., Xiao, H. and Lu, Y. (2009) A Brief Introduction on the Clinical Application of Bian-Stone (Stone Needle): Experience of Kong Kit Chee in Hong Kong. International Journal of Clinical Acupuncture, 18, 194-198.

[143] Kong, K.C., Lo, P.L. and Yuan, L. (2011) A Clinical Observation on Treating 30 Cases of Callan Pseudo Myopia with Bian Stone Therapy. International Journal of Acupuncture, 20, 
19-24.

[144] Shields, M.B. (2008) Normal-Tension Glaucoma: Is It Different from Primary Open-Angle Glaucoma? Current Opinion in Ophthalmology, 19, 85-88.

http://dx.doi.org/10.1097/ICU.0b013e3282f3919b

[145] Berdahl, J.P., Fautsch, M.P., Stinnett, S.S. and Allingham, R. (2008) Intracranial Pressure in Primary Open Angle Glaucoma, Normal Tension Glaucoma, and Ocular Hypertension: A Case-Control Study. Investigative Ophthalmology \& Visual Science, 49, 5412-5418.

http://dx.doi.org/10.1167/iovs.08-2228

Submit or recommend next manuscript to SCIRP and we will provide best service for you:

Accepting pre-submission inquiries through Email, Facebook, LinkedIn, Twitter, etc. A wide selection of journals (inclusive of 9 subjects, more than 200 journals)

Providing 24-hour high-quality service

User-friendly online submission system

Fair and swift peer-review system

Efficient typesetting and proofreading procedure

Display of the result of downloads and visits, as well as the number of cited articles Maximum dissemination of your research work

Submit your manuscript at: http://papersubmission.scirp.org/

Or contact ojmip@scirp.org 